\title{
Full-Set Transformer Protection Barrier Manufacturing and Technology
}

TCF-19-17721

K. Ryan Bratton

ME MS

Henry Chu

ME PhD

Todd L Johnson

$M E B S$

IIdaho National Laboratory 


\section{DISCLAIMER}

This information was prepared as an account of work sponsored by an agency of the U.S. Government. Neither the U.S. Government nor any agency thereof, nor any of their employees, makes any warranty, expressed or implied, or assumes any legal liability or responsibility for the accuracy, completeness, or usefulness, of any information, apparatus, product, or process disclosed, or represents that its use would not infringe privately owned rights. References herein to any specific commercial product, process, or service by trade name, trade mark, manufacturer, or otherwise, does not necessarily constitute or imply its endorsement, recommendation, or favoring by the U.S. Government or any agency thereof. The views and opinions of authors expressed herein do not necessarily state or reflect those of the U.S. Government or any agency thereof. 


\title{
Full-Set Transformer Protection Barrier Manufacturing and Technology
}

\author{
TCF-19-17721
}

K. Ryan Bratton
ME MS

September 2020

\author{
Idaho National Laboratory \\ National \& Homeland Security \\ Idaho Falls, Idaho 83415
}

http://www.inl.gov

\author{
Prepared for the \\ U.S. Department of Energy \\ Office of Technology Transitions \\ Under DOE Idaho Operations Office \\ Contract DE-AC07-05ID14517
}


Page intentionally left blank 


\section{ABSTRACT}

This Technology Commercialization Fund (TCF) project provided the design, fabrication, and testing a full-scale prototype "Corner Unit" protective barrier to provide seamless $360^{\circ}$ perimetrical protection for highly expensive power generation or transmission infrastructure. The Corner Unit will seamlessly match up to the existing A-Frame design to form the $360^{\circ}$ protection desired from industry. This TCF project also demonstrated how commercial industry could fabricate and deliver the full-scale barriers to remote locations. 
Page intentionally left blank 


\section{SUMMARY}

In the 2013 MetCalf attack, a rogue attack caused $\$ 15 \mathrm{M}$ in damages to power generation and transmission equipment. In 2015, Idaho National Laboratory undertook a project to preemptively answer the call of industry for large electrical infrastructure project and created the successful AFrame Transformer Barrier. This TCF project set out and accomplished its goal of designing, fabricating, and testing a full-scale prototype "Corner Unit" protective barrier to provide seamless $360^{\circ}$ perimetrical protection for highly expensive power generation or transmission infrastructure.

The Corner Unit will seamlessly match up to the existing A-Frame design to form the $360^{\circ}$ protection desired from industry. This work helps to fulfill the requirement set forth in the federal reliability standard (CIP-014-2), published in 2015, mandating all transmission stations, substations, and control centers should be protected. The Corner Unit was designed at Idaho National Laboratory then sent out to a small business partner, Waltonen Engineering Inc., to fabricate one Corner Unit and one A-Frame Unit as well as provide feedback to make the design better translate at the market scale. Written also in the contract with Waltonen was to provide the cost of manufacturing of the Corner Unit and A-Frame at market scales, up to 500 units.

Once fabricated, the units were sent to the Idaho National Laboratory National Security Test Range to be ballistically and explosively validated. The Corner Unit was ballistically validated with 0.50 caliber ball and armor piercing rounds. The Corner Unit passed the test by not allowing any rounds to reach behind the protection line where any valuable equipment could be located. The A-Frame was explosively validated with a 5-pound C4 charge in which the unit survived and denied personnel or line-of-sight access through the barrier. 
Page intentionally left blank 


\section{CONTENTS}

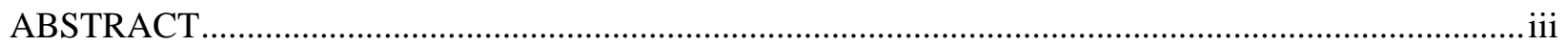

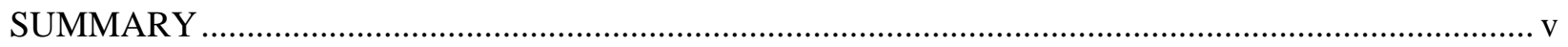

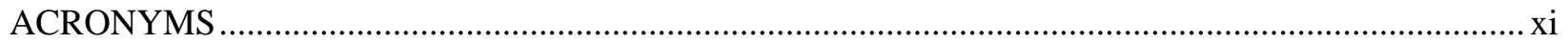

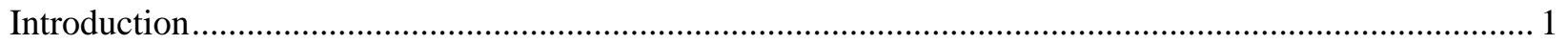

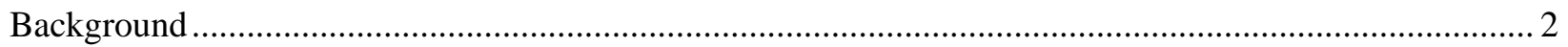

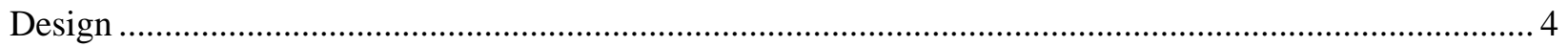

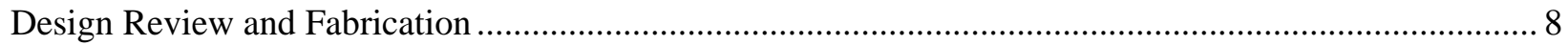

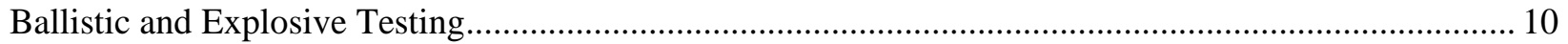

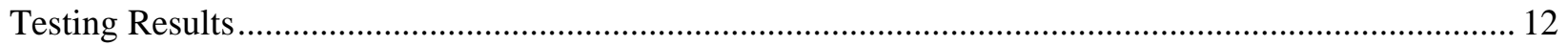

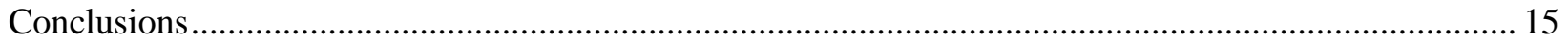

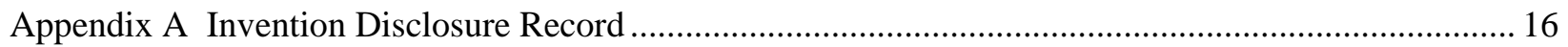

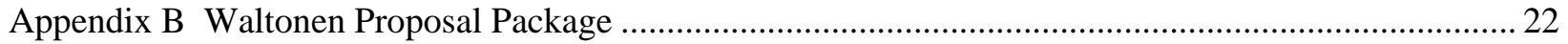


Page intentionally left blank 


\section{FIGURES}

Figure 1. The first full-scale "A-Frame” Prototype Barrier shown protecting a large transformer. .............2

Figure 2. Conceptual model illustrating the need for a corner barrier to provide seamless perimetrical protection. 3

Figure 3. An isometric view of the final Transformer Barrier Corner Unit design. 4

Figure 4. An isometric view of the final and fabricated design of the A-Frame Barrier design. .5

Figure 5. 3D printed model exploded view of one Corner Unit flanked by two A-Frame units. 6

Figure 6. 3D printed model of Corner Unit mated with two A-Frames forming L-shape illustrating seamless protection offered through the combination of these two barrier types.

Figure 7. Fabrication of A-Frame Unit illustrating a) A-Frame "Top Hat" section that provides upper protection for the A-Frame Unit. b) A single armor cassette prepped for loading into one side of the A-Frame Unit. c) One side of A-Frame Unit with a single armor cassette installed. d) Completed A-Frame Unit with both side armor cassettes installed and Top Hat installed.

Figure 8. Corner Unit Fabrication showing a) Corner Unit with lower section of armor cassette installed. b) One completed section of Corner Unit Transformer Barrier.

Figure 9. Corner Unit flanked by A-Frame Units to show seamless protection on corners of AFrame protection lines.

Figure 10. Experimental setup for ballistic verification of armor panels for Corner Unit

Figure 11. Explosive charge placed on one of the armor panels of the A-Frame structure to test survivability of unit when facing small 5-pound $\mathrm{C} 4$ explosive threat.

Figure 12. Images of the Corner Unit's armor plate after being shot by 0.50 caliber ammunition a) armor plate containing shots 1 (ball) and 2 (AP), b) shots 3-7 (AP), and divots in rear concrete resulting from penetrating shots 3 and 7 .

Figure 13. Time-lapse images showing the event of 0.50 caliber bullet impact, disintegration, and propagation of fragments at a) impact, b) $500 \mathrm{~ms}$ after impact, c) $1000 \mathrm{~ms}$ after impact, and d) $1500 \mathrm{~ms}$ after impact against the Corner Unit's armor panel.

Figure 14. Pictures of A-Frame Unit post $\mathrm{C} 4$ charge explosion showing a) square hole formed through front armor and $b$ ) perforation through the bottom rear armor.

Figure 15. 5-pound C4 charge test against the A-Frame Unit illustrating a) initial blast and impact of debris behind unit, b) impact of larger debris behind unit; no movement of unit yet observed, c) movement of lower part of unit as Top Hat flexes forward, d) lower part of unit comes to rest and Top Hat returns to proper position in the unit.

\section{TABLES}

Table 1. Cost Estimates of A-Frame Unit and Corner Unit Per number of manufactured units.

Table 2. Parameters for each of the seven shots used against the Corner Unit's armor plate to evaluate the ballistic performance of the armor package. 
Page intentionally left blank 


\section{ACRONYMS}

$\begin{array}{ll}\text { AP } & \text { Armor Piercing } \\ \text { COTS } & \text { Commercial off-the-shelf } \\ \text { DOE } & \text { Department of Energy } \\ \text { HV } & \text { High Voltage } \\ \text { IDR } & \text { Invention Disclosure Record } \\ \text { INL } & \text { Idaho National Laboratory } \\ \text { LDRD } & \text { Laboratory Directed Research \& Development } \\ \text { ms } & \text { millisecond } \\ \text { NSTR } & \text { National Security Test Range } \\ \text { TCF } & \text { Technology Commercialization Fund } \\ \text { TRL } & \text { Technology Readiness Level } \\ \text { UL } & \text { Underwriters Laboratory }\end{array}$


Page intentionally left blank 


\section{Introduction}

The most crucial components of the U.S. electricity generation and transmission system are certain types of high voltage (HV) transformers and towers supporting transmission lines in remote locations across the country. Specifically, these transformers include those with a high value or those that require a long lead time and are difficult to replace. These crucial components are vulnerable to major rogue assaults.

Idaho National Laboratory (INL) Defense Systems Division has developed, designed, and manufactured a full-scale armored barrier to protect electrical transformers and other critical assets against rogue gunfire assault. Subsequent to an INL Industry Day live-fire demonstration, physical security managers from several large utility companies had inquired if a corner structure could also be developed and demonstrated to provide seamless perimetrical protection for the aforementioned types of transformers at remote substations. As a result of the above discussions funding was sought through the Technology Commercialization Fund (TCF) to satisfy the perimetrical protection request from industry and mature the existing barrier technology.

This TCF project included the design, manufacture, and testing of a companion Corner Barrier to the First Prototype Barrier also known as the A-Frame Barrier. Additionally, a second unit of the A-Frame Barrier was constructed to demonstrate the seamless perimetrical protection offered when the Corner Barrier is flanked by A-Frame Barriers. This project demonstrated the capability, scalability, and maturity of the technology, and worked with and continued to build relationships with the commercial sector to show how the product may be transferred to this industry. In an effort to move the Corner Unit and A-Frame to market, cost estimates for variable amounts of units using Waltonen's industrial fabrication method were forecasted for up to 500 units manufactured. 


\section{Background}

In April 2013, the Metcalf Transmission Substation near San Jose, California sustained significant damage due to a planned gunfire attack in which gunmen fired on equipment located inside the substation. Upon hearing of this attack, INL Defense Systems researchers observed the need for a barrier system to protect against such attacks.

In 2015, a Federal Reliability Standard (CIP-014-2) was published mandating that transmission stations, substations, and control centers should be protected. INL Defense Systems developed, designed, and manufactured a full-scale armored First Prototype Barrier, Figure 1, to protect electrical transformers and other vulnerable equipment against rogue gunfire assault. This work was funded by the Laboratory Directed Research \& Development (LDRD) program. The full-scale (TRL 7) barrier has been tested with successful results in protecting against ballistic attacks over UL 752, Level 10 in live-fire tests. The protective barrier was designed with readily available commercial off-the-shelf (COTS) materials and can be installed with equipment already in use by electric utility companies. The barrier is modular, and armor panels may be replaced without having to replace the entire protection section, such as in single-panel fencepost type of barrier. In addition, the armor panels may be readily retrofitted to meet other specific threats.

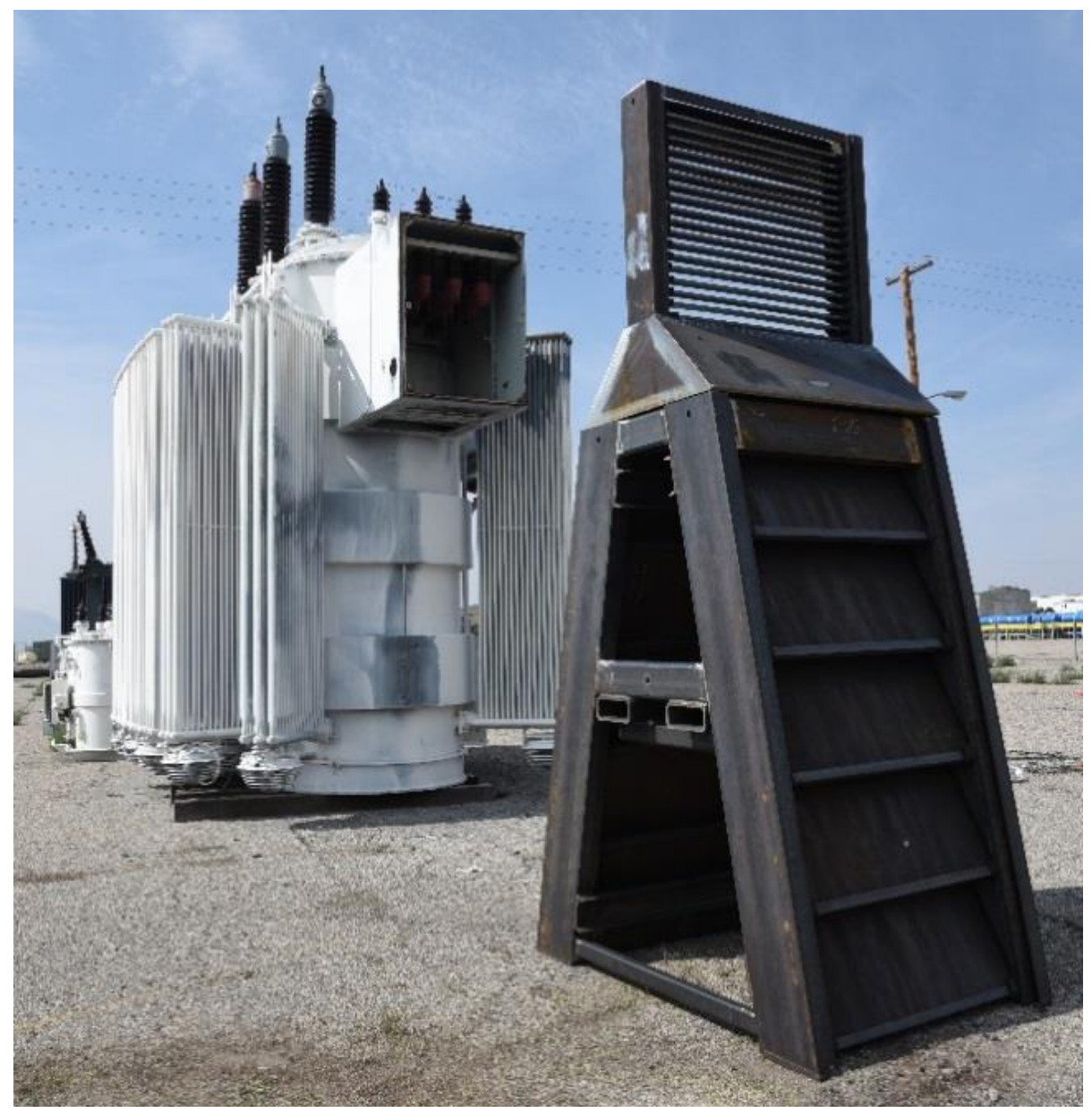

Figure 1. The first full-scale "A-Frame" Prototype Barrier shown protecting a large transformer. 
Subsequent to an Industry Day live-fire demonstration at INL, physical security managers from several large utility companies inquired if a "Corner Barrier" structure, see Figure 2, could also be developed to provide seamless perimetrical protection for transformers at remote substations that have a high value or require a long lead time and are difficult to replace. Preliminary talks have been held with the security officers and mangers of Southern Company and American Electric Company regarding commercialization and deployment of this invention.

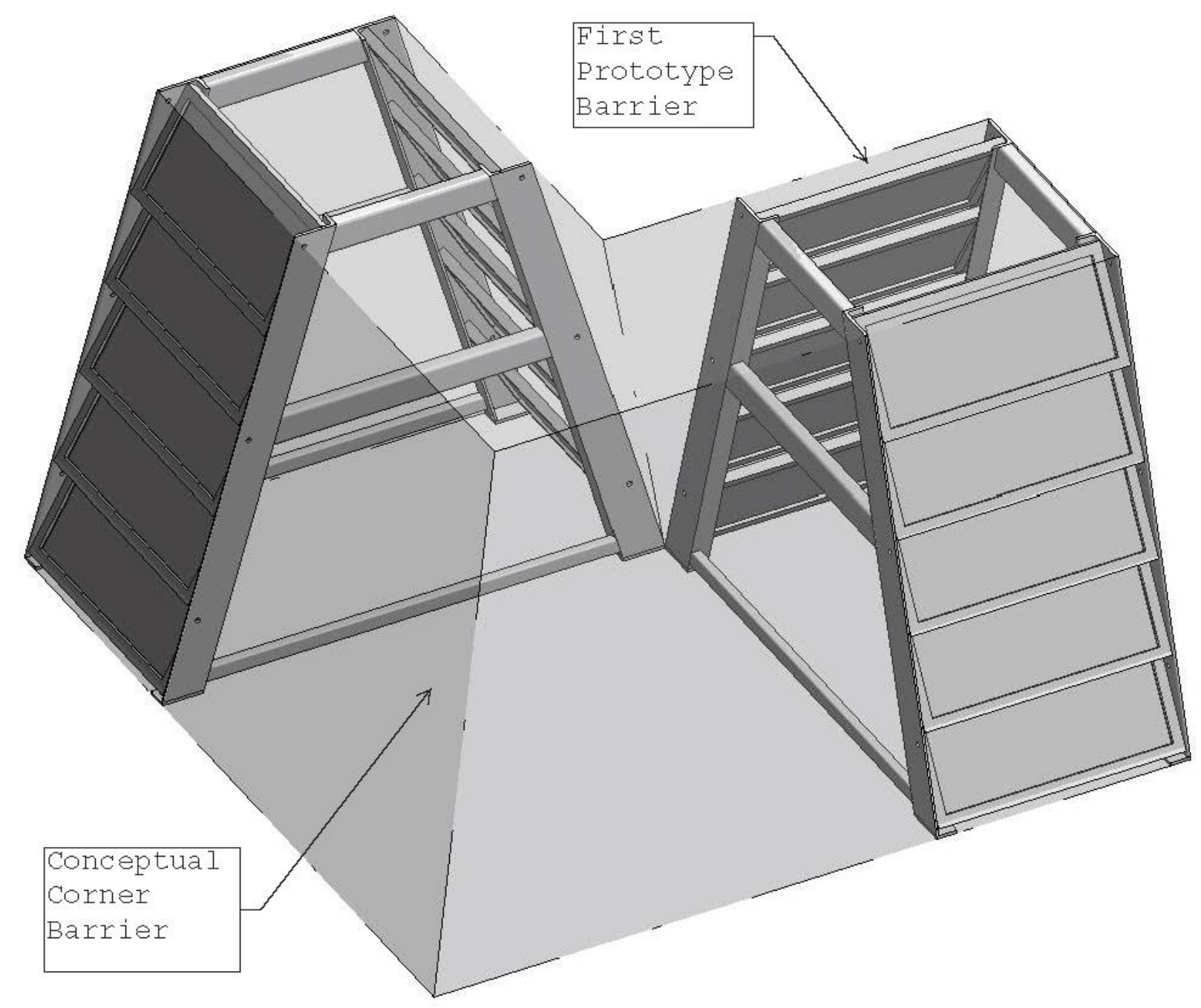

Figure 2. Conceptual model illustrating the need for a corner barrier to provide seamless perimetrical protection.

The current TCF project designed, manufactured, and tested a companion Corner Barrier to complement the patented A-Frame Barrier. Additionally, a second unit of the A-Frame Barrier unit was constructed such that together, all three units formed an L-shaped section to block any line-of-sight necessary to carry out any attacks from gunfire and explosives. The seamless protection offered by this technology is applicable, if not necessary, for any electrical transformer, footing of transmission tower, or other vulnerable asset critical to the nation's electric supply system. 


\section{Design}

As with the A-Frame barrier, the frame-support structure and armor components of the corner barrier was designed with commercially available materials and uses industrial manufacturing processes readily available at many similarly equipped and qualified manufacturing facilities. All barrier units are designed to be field assembled, as well as movable and repairable with commercial utility-based equipment.

The corner barrier detailed design evaluated the best configuration for corner protection. The design evaluated various shapes to determine: a final configuration for ballistic and explosive protection, the ability to replace armor panels and to lift and move the structure, minimize material cost, maximize material performance, ease of manufacturing perspective, mate up to the existing A-Frame Barrier, and integrate into seamless perimetric protection.

During the design, the INL acquired the services of Waltonen Engineering, Inc, a fullservice design, engineering, and manufacturing company located in Warren, Michigan. This contract with Waltonen was to review both the Corner Unit and A-Frame designs for ease of manufacturing and cost efficiencies. This review lead to several suggestions being implemented into the final designs. An isometric view of the final Corner Unit design is shown in Figure 3. A provisional patent has been submitted for the Corner Units final design. The Invention Disclosure Record (IDR) of this design is given in Appendix A.

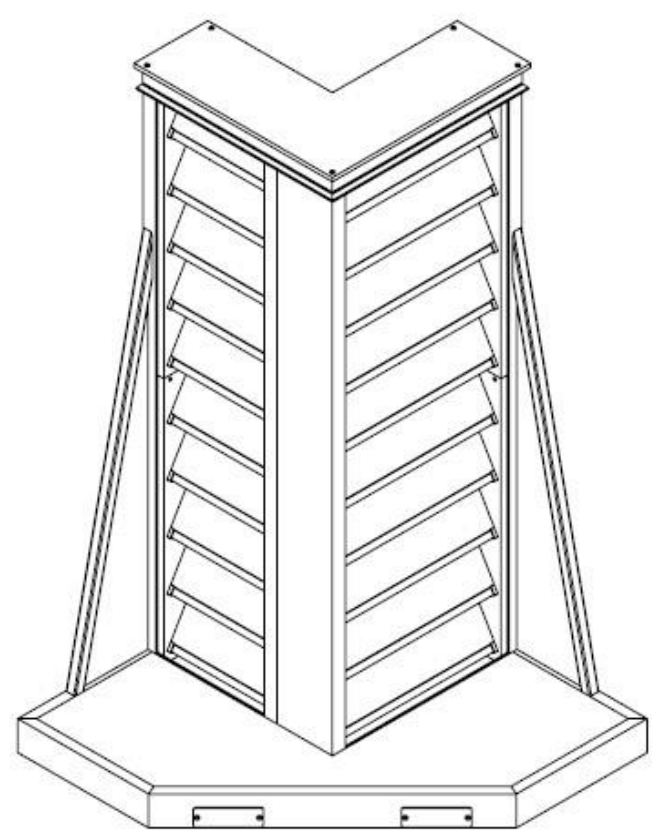

Figure 3. An isometric view of the final Transformer Barrier Corner Unit design. 
The final Corner Unit design includes a structural steel base, with forklift pockets. The base is filled with concrete either during manufacturing or in the field. Attached to the base are four $\mathrm{C}$ channels that form two pockets that the armor cassettes to slide into. Each pocket receives two armor cassettes to minimize the required lifting height to load the cassettes in the pockets.

In addition, the initial prototype A-frame design drawings were updated to include relines, lessons learned during the initial fabrication, and cost efficiency suggestions from Waltonen. The final accepted design and fabricated model for the A-Frame Barrier is shown in Figure 4.

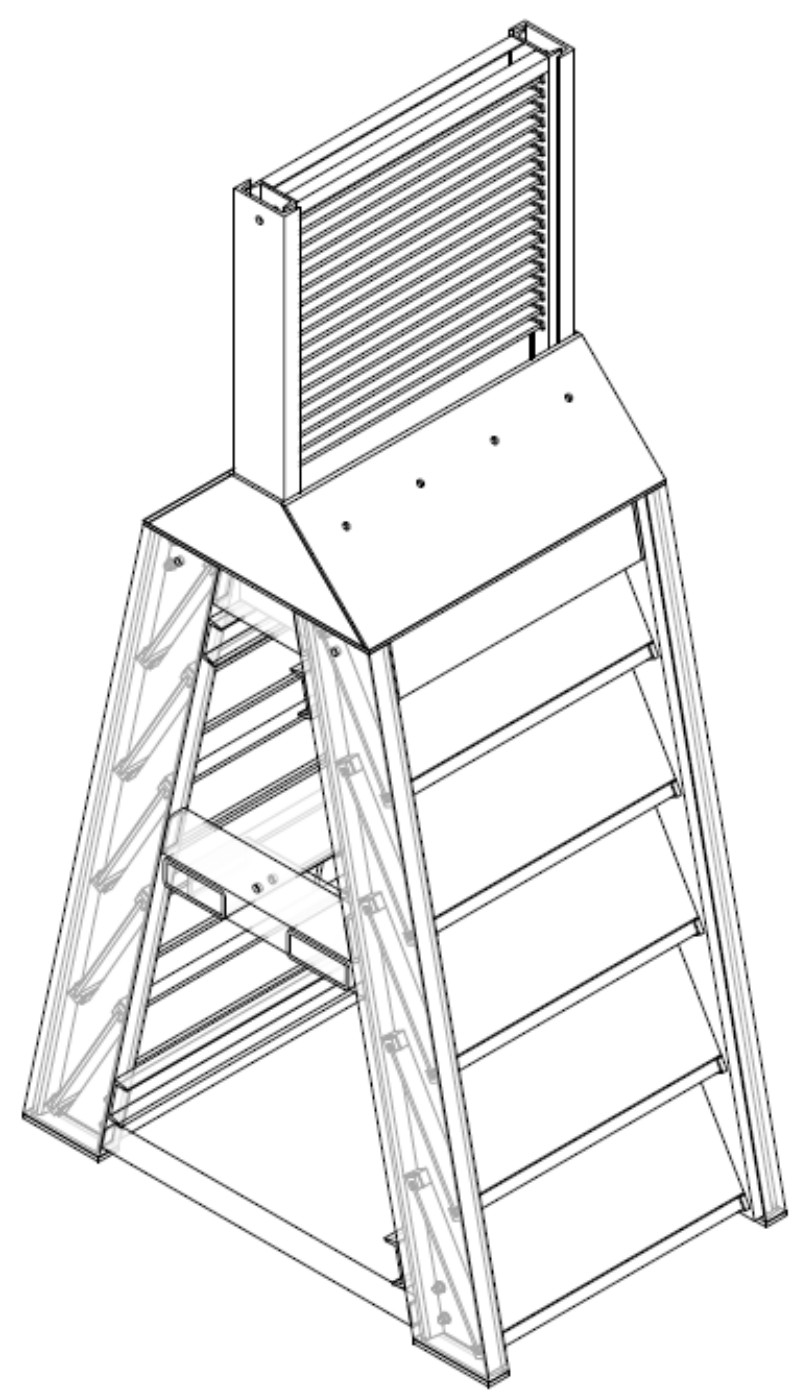

Figure 4. An isometric view of the final and fabricated design of the A-Frame Barrier design. 
To verify the design, fit, and unit configuration, scaled down 3D models of the Corner Unit and A-Frames structures were printed. The models confirmed that the integration of the Corner Unit with the A-Frame provided full perimetric protection with no gaps in coverage. (See Figures $5 \& 6$ ).

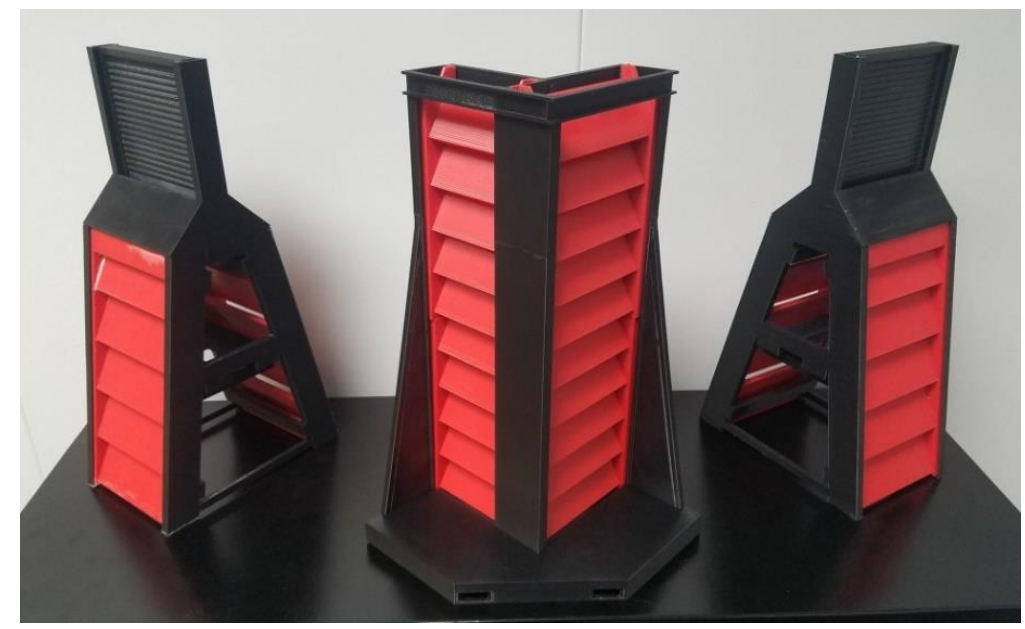

Figure 5. 3D printed model exploded view of one Corner Unit flanked by two A-Frame units.

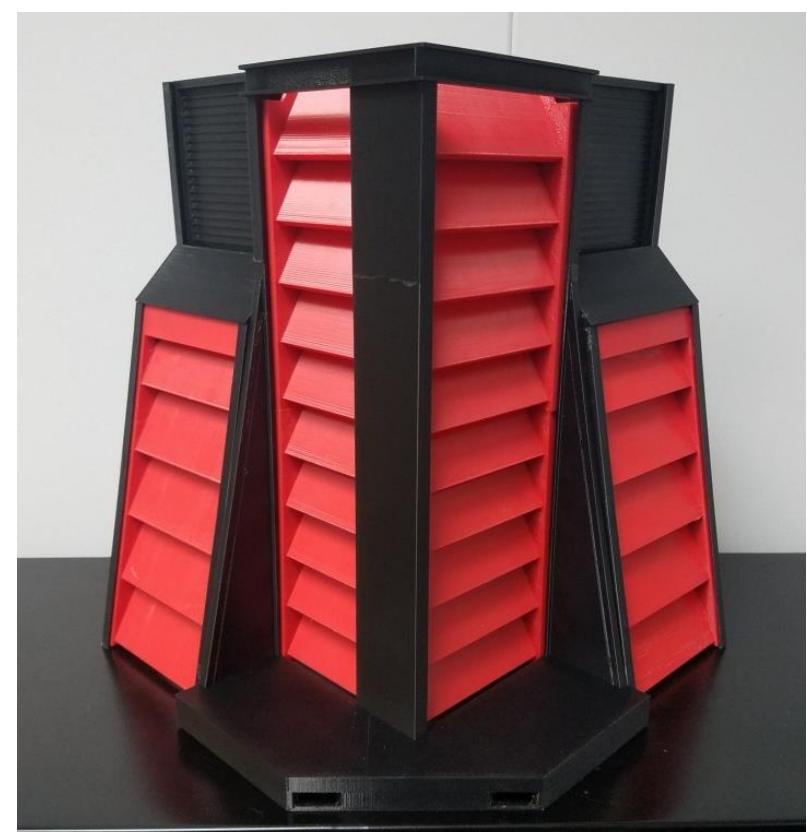

Figure 6. 3D printed model of Corner Unit mated with two A-Frames forming L-shape illustrating seamless protection offered through the combination of these two barrier types.

The key features of the Corner Unit are its ease of construction/deconstruction, modular nature, freestanding structure, and ballistic rating up to UL level 10 threats. The ease of construction allows for the rapid deployment, compared to fence-type barriers, of the Corner Unit. True to its modular nature, to construct the Corner Unit first the frame is erected, concrete 
is poured into the base form, and armor panels are inserted. The modular nature also allows for the replacement or downsizing of armor plates according to anticipated threat level or capitaldriven design. The freestanding design reduces the cost of installation and deployment allowing the Corner Unit to be deployed and redeployed without expensive umbilical equipment (ribs and anchors). The existing product on the market is designed to mitigate up to a UL level 5 threat. The Corner Unit will be deployed with armor plate rated at a UL level 10 threat allowing the Corner Unit to perform at a significantly higher level. 


\section{Design Review and Fabrication}

Preliminary conversations with several private industry companies have garnered their interest as future partnering organizations in implementing or manufacturing the protective barriers. After consulting industry, Waltonen Engineering, Inc. was selected for A-Frame and Corner Unit Barrier design review and fabrication of a prototype Corner Unit and a second AFrame Unit.

Waltonen's design review was aimed at streamlining the conceptual design and fabrication drawings for Corner Unit and streamlining the drawings for the existing A-Frame design. The objective of the design review for the drawings was to allow an industry entity to provide a manufacturing perspective as well as reduce the time needed to migrate to market production. Waltonen was able to provide invaluable feedback to the design and manufacturing of the Corner Unit and A-Frame drawings. Comments included changes in design and assembly to reduce the machining time and overall cost.

The fabrication of the Corner Unit and the second A-Frame Unit were conducted by Waltonen at their facility in Warren, Michigan (See Figures $7 \&$ 8). All materials were ordered by the manufacturer to emulate a market-like production scenario of both units. The units' frames were constructed from A36 carbon steel while the armor plates were constructed from MIL-DTC 46100 high hardness steel and these materials are commercially available. As the armor hardness is a critical component to the units' performance, a hardness measurement program was written and given to Waltonen to verify the MIL-DTC 46100 plate procurement and will be used in industrial manufacturing.

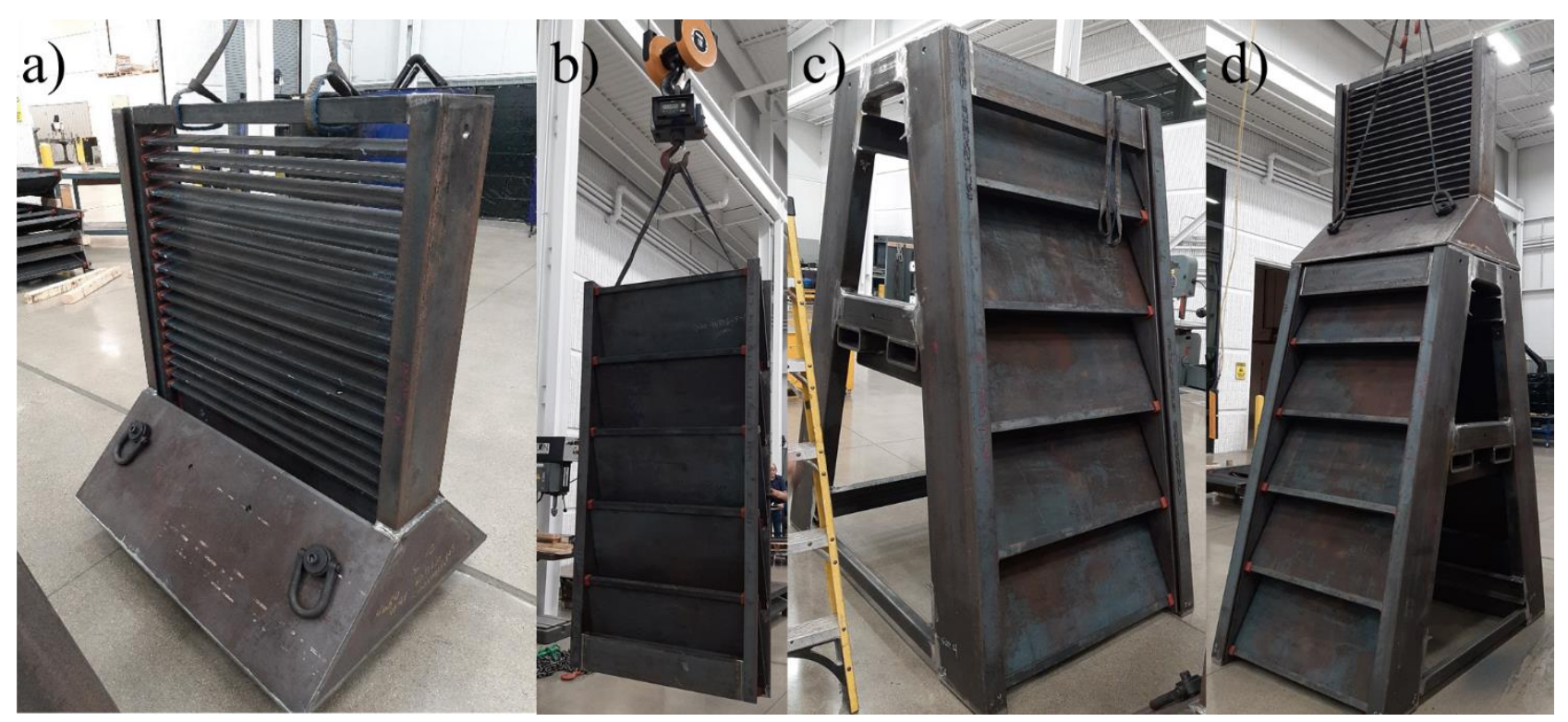

Figure 7. Fabrication of A-Frame Unit illustrating a) A-Frame "Top Hat" section that provides upper protection for the A-Frame Unit. b) A single armor cassette prepped for loading into one side of the A-Frame Unit. c) One side of A-Frame Unit with a single armor cassette installed. d) Completed A-Frame Unit with both side armor cassettes installed and Top Hat installed. 


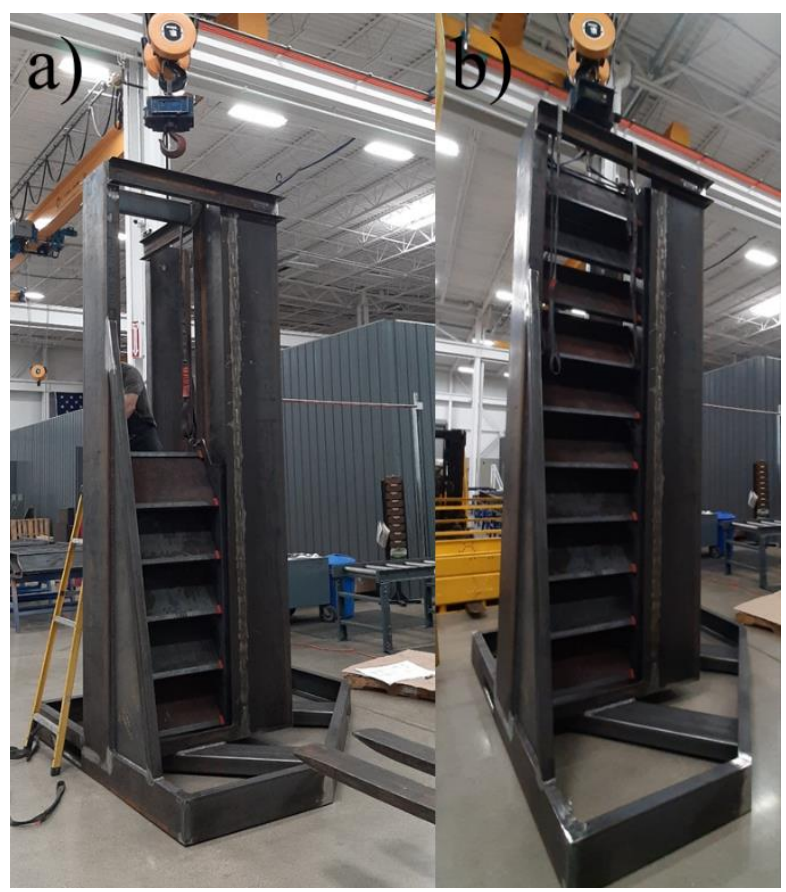

Figure 8. Corner Unit Fabrication showing a) Corner Unit with lower section of armor cassette installed. b) One completed section of Corner Unit Transformer Barrier.

Additionally, one of the primary design criteria to be met by this design is to be liftable by normal power utilities derrick trucks or not require special equipment to assemble the Corner and A-Frame Units. All individual pieces were weighed and were under the maximum lift weight for a standard derrick truck. The final acceptance testing was conducted via video recording showing the structures and armor cassettes loaded into these structures. It is crucial that the armor cassettes be loaded into the standalone structures without any specialized equipment. The machinists/lift operators were able to successfully load the armor cassettes into the unit structures without extensive prior description due to the units' intuitive designs.

Overall, this process aided greatly in the transition to market fabrication through clarification of design while also progressing the design from prototypical to marketable. Waltonen provided a cost estimate per unit volume scaling from 1-10 to 101-500. Summarized cost estimates are in Table 1 and in Appendix B (Appendix G of proposal).

\begin{tabular}{|c|c|c|c|}
\multicolumn{2}{c|}{ A-Frame } & \multicolumn{2}{c|}{ Corner Unit } \\
\hline $\begin{array}{c}\text { Number of Units } \\
\text { Manufactured }\end{array}$ & Cost & $\begin{array}{c}\text { Number of Units } \\
\text { Manufactured }\end{array}$ & Cost \\
\hline $1-10$ & $\$ 44,682.00$ & $1-10$ & $\$ 46,187.00$ \\
\hline $11-50$ & $\$ 44,976.49$ & $11-50$ & $\$ 46,265.91$ \\
\hline $51-100$ & $\$ 43,867.20$ & $51-100$ & $\$ 44,737.19$ \\
\hline $101-500$ & $\$ 42,646.34$ & $101-500$ & $\$ 42,892.43$ \\
\hline
\end{tabular}

Table 1. Cost Estimates of A-Frame Unit and Corner Unit Per number of manufactured units. 


\section{Ballistic and Explosive Testing}

The Corner Unit is designed to be flanked by two A-Frames to create $360^{\circ}$ perimeter of armor protection for expensive electrical or power generation equipment. The Corner Unit and accompanying A-Frames are shown in Figure 9. In a real setup, the A-Frame is equipped with ports that allow steel cabling of one A-Frame to its neighbors making it difficult to pull the units apart or topple the units to gain access. A functional requirement of both the Corner Unit and the A-Frame Unit is that they can be assembled, sited, and configured using available utility equipment trucks without requiring a crane or other special equipment. These barriers were assembled at the INL National Security Test Range (NSTR) by power utility personnel without prior experience with the units. The utility crews were able to put together the units without rigorous instruction satisfying this criterion.

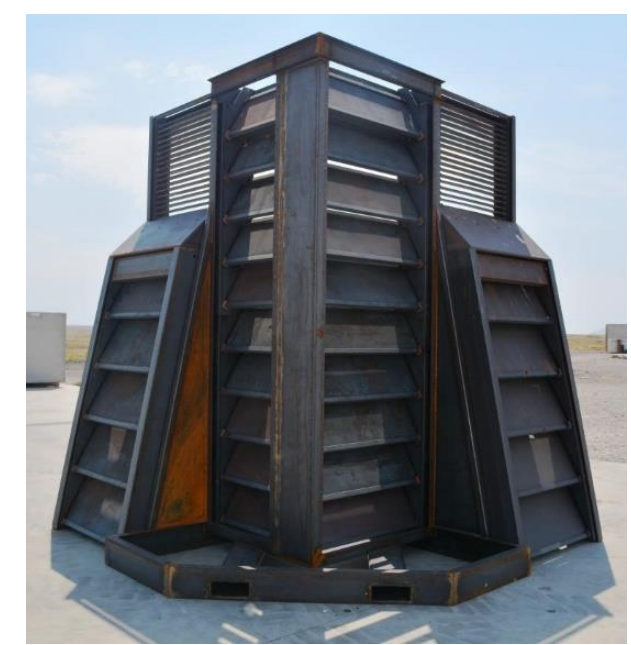

Figure 9. Corner Unit flanked by A-Frame Units to show seamless protection on corners of AFrame protection lines.

Ballistic testing of the Corner Unit transformer barrier was executed to ensure that the unit meets a UL level 10 ballistic threat mitigation. The testing ammunition types were 0.50 caliber ball and armor piercing fired from a 20-foot distance. High speed videography was employed to capture the bullet/armor reaction as well as bullet impact velocity. Overall, one round of the ball 0.50 caliber and 6 rounds of the armor piercing 0.50 caliber were employed to verify the ballistic protection level of the Corner Unit ${ }^{\mathrm{a}}$. Experimental setup is shown in Figure 10.

\footnotetext{
${ }^{a}$ Note that the 0.50 caliber armor piercing ammunitions exceeded both the UL752 Level 10 and NIJ 0108.01 Level IV requirements and their uses were to estimate the upper bounds of protection capability.
} 


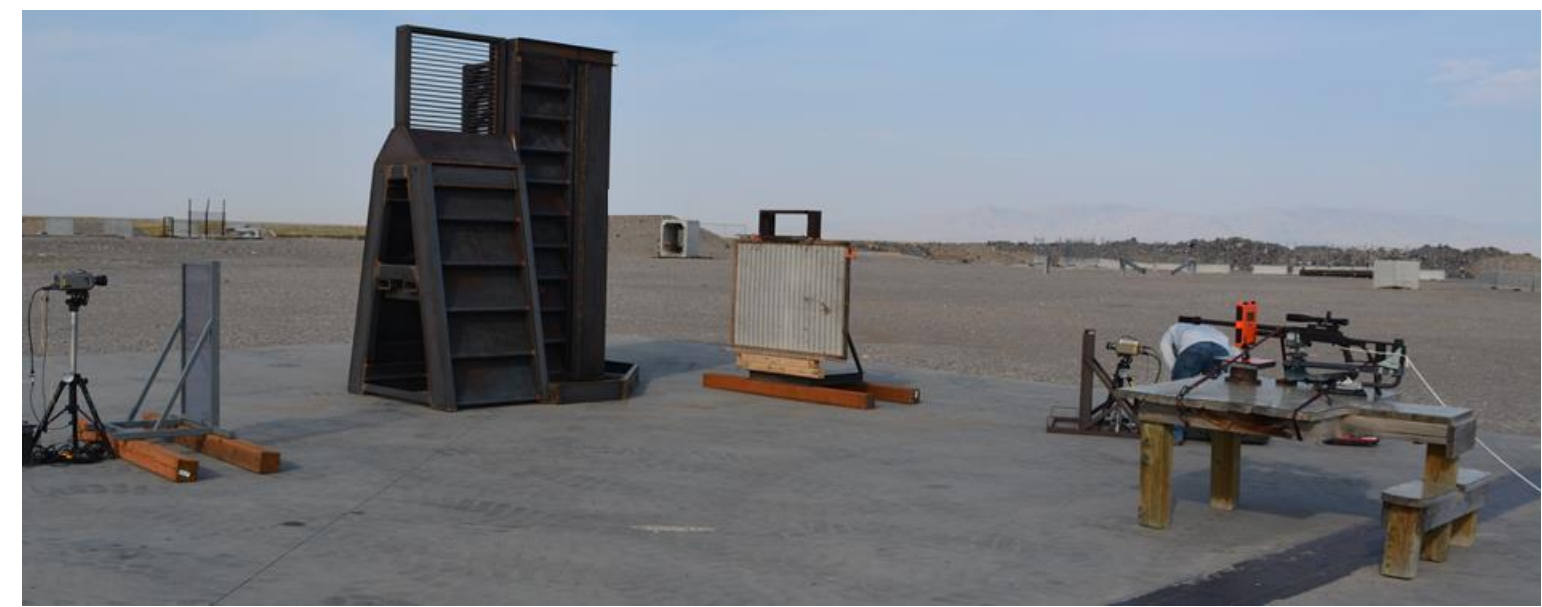

Figure 10. Experimental setup for ballistic verification of armor panels for Corner Unit.

The A-Frame barrier underwent ballistic testing in the previous project in 2015 and was not tested again ballistically as the barrier passed UL level 10 ballistic threats. In this work, the A-Frame was also tested using a small 5-pound C4 explosive charge on an armor plate to emulate a small explosive attack on the barrier system. The explosive testing also employed high speed video to capture the reaction of the A-Frame to the explosive charge. Figure 11 displays the explosive charge on the A-Frame armor plate.

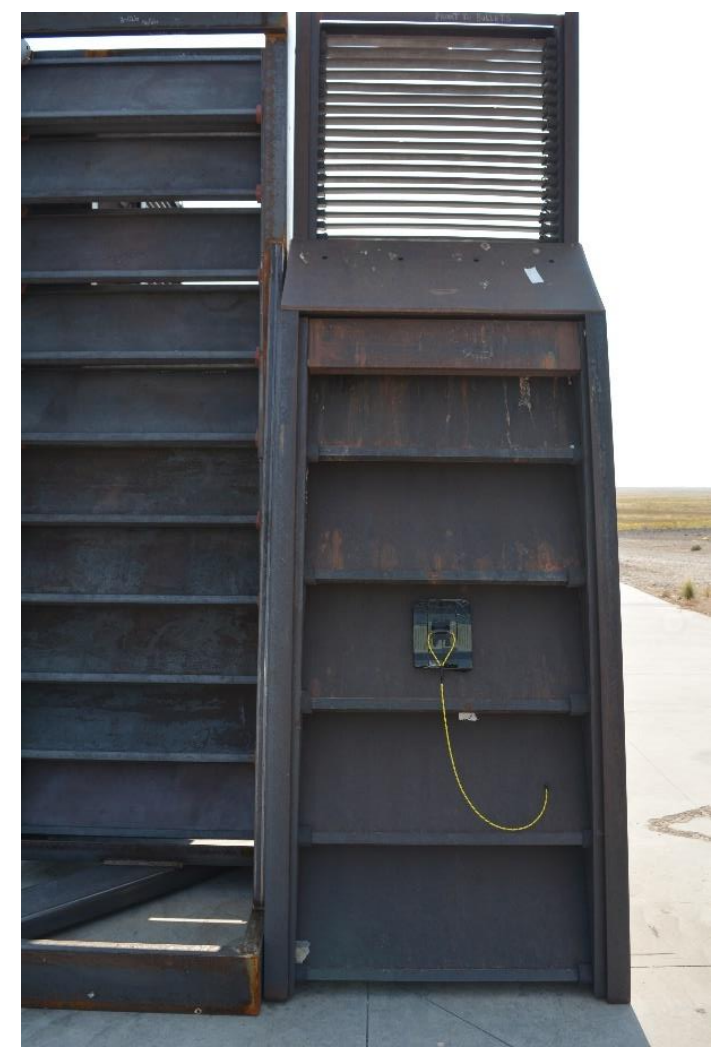

Figure 11. Explosive charge placed on one of the armor panels of the A-Frame structure to test survivability of unit when facing small 5-pound C4 explosive threat. 


\section{Testing Results}

Two types of 0.50 caliber ammunition were used to test the ballistic performance of the Corner Unit armor plate. The two types of ammunition used were 0.50 ball and 0.50 armor piercing (AP) rounds. In total, seven shots were used to evaluate the performance of the armor plate. Table 1 displays the details for each of the seven shots used to evaluate the performance of the Corner Unit.

\begin{tabular}{|c|c|c|c|c|c|c|c|c|}
\hline Shot Number & Date & Time & Temp & Caliber & $\begin{array}{c}\text { Bullet } \\
\text { Mass } \\
\text { (grains) }\end{array}$ & $\begin{array}{c}\text { Powder } \\
\text { Mass } \\
\text { (grains) }\end{array}$ & $\begin{array}{c}\text { Velocity } \\
\text { (ft/s) }\end{array}$ & Comments \\
\hline Shot 1 & $8 / 18 / 2020$ & 2:48 p.m. & $899 \mathrm{~F}$ & 0.50 Ball & 860 & 227 & 2652 & - No penetration \\
\hline Shot 2 & $8 / 18 / 2020$ & 3:12 p.m. & $89 \mathrm{~F}$ & $0.50 \mathrm{M} 2 \mathrm{AP}$ & 693 & 227 & 2620 & \begin{tabular}{|l} 
- Penetrated armor \\
- Bullet deflected downward \\
- Slight spalling of concrete were deflected bullet hit concrete \\
( $421 / 2 "$ below and $22 "$ behind bullet hole in armor) \\
- Very little damage to plywood witness plate behind armor
\end{tabular} \\
\hline Shot 3 & $8 / 19 / 2020$ & 9:30 a.m. & $74 \mathrm{~F}$ & $0.50 \mathrm{M} 2 \mathrm{AP}$ & 691 & 227 & 2658 & $\begin{array}{l}\text { - Penetrated armor } \\
\text { - Bullet deflected downward } \\
\text { - Slight spalling of concrete were deflected bullet hit concrete } \\
\text { (57 1/4" below and } 37 \text { " behind bullet hole in armor) } \\
\text { - Very little damage to plywood witness plate behind armor }\end{array}$ \\
\hline Shot 4 & $8 / 19 / 2020$ & 9:50 a.m. & $72 \mathrm{~F}$ & $0.50 \mathrm{M} 2 \mathrm{AP}$ & 689 & 227 & 2694 & - No penetration \\
\hline Shot 5 & $8 / 19 / 2020$ & 10:05 a.m. & $75 \mathrm{~F}$ & $0.50 \mathrm{M} 2 \mathrm{AP}$ & 694 & 227 & 2578 & - No penetration \\
\hline Shot 6 & $8 / 19 / 2020$ & 10:14 a.m. & $75 \mathrm{~F}$ & $0.50 \mathrm{M} 2 \mathrm{AP}$ & 694 & 227 & 2579 & - No penetration \\
\hline Shot 7 & $8 / 19 / 2020$ & 10:24 a.m. & $75 \mathrm{~F}$ & $0.50 \mathrm{M} 2 \mathrm{AP}$ & 693 & 227 & 2591 & $\begin{array}{l}\text { - Penetrated armor } \\
\text { - Bullet deflected downward } \\
\text { - Slight spalling of concrete were deflected bullet hit concrete } \\
\text { (55 } 1 / 2 \text { " below and } 36 " \text { behind bullet hole in armor) } \\
\text { - Very little damage to plywood witness plate behind armor }\end{array}$ \\
\hline
\end{tabular}

Table 2. Parameters for each of the seven shots used against the Corner Unit's armor plate to evaluate the ballistic performance of the armor package. Note: $0.50 \mathrm{M} 2 \mathrm{AP}$ rounds are beyond UL 752 level 10.

Out of the seven shots, 3 penetrated the armor plate but did not cause significant damage to the witness board located behind the armor plate. The rounds that did penetrate the armor plate were deflected through the plate thickness and impacted the concrete directly behind the Corner Unit. These impacts on the concrete were 22" - 36" (depending on armor plate height) horizontally from the exit point of the armor plate which lie on the back of the Corner Unit concrete reinforcement pad. With this result, no bullets that penetrated the armor were able to escape past the barrier nor reach any critical components being protected by the Corner Unit. The armor panels shot by the 0.50 caliber rounds is shown in Figure 12 .

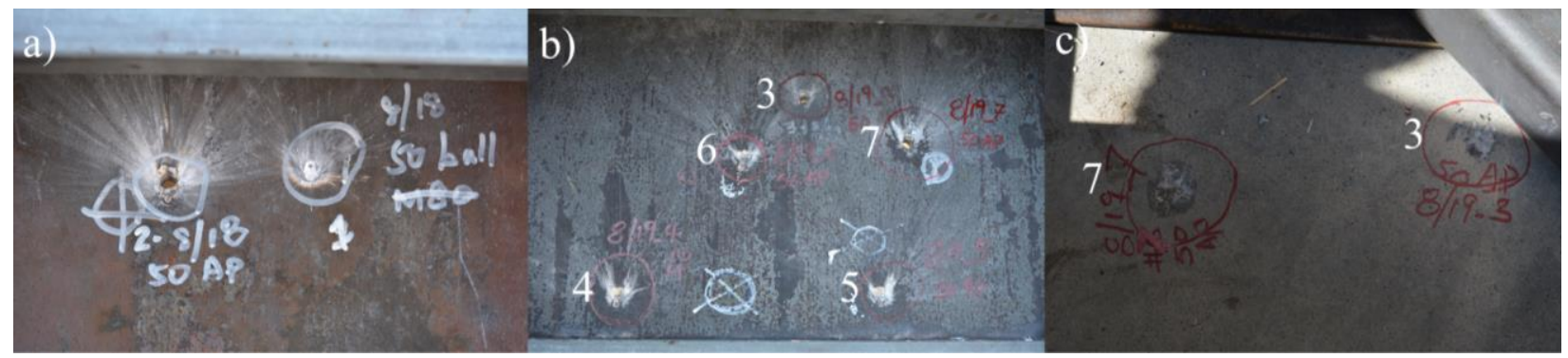

Figure 12. Images of the Corner Unit's armor plate after being shot by 0.50 caliber ammunition a) armor plate containing shots 1 (ball) and 2 (AP), b) shots 3-7 (AP), and divots in rear concrete resulting from penetrating shots 3 and 7 . 
The majority of the 0.50 caliber projectiles disintegrated upon impacting the armor plate as shown in Figure 13. The bullet impacts the armor plate and the debris of the plate and projectile is directed upwards due to the momentum of the projectile. As seen in Figure 13, this event creates many heated particles that flow up the surface of the plate until the particles impact the edge stiffener then flow horizontally as time progresses. This phenomenon is seen in both the penetrating and non-penetrating shots.

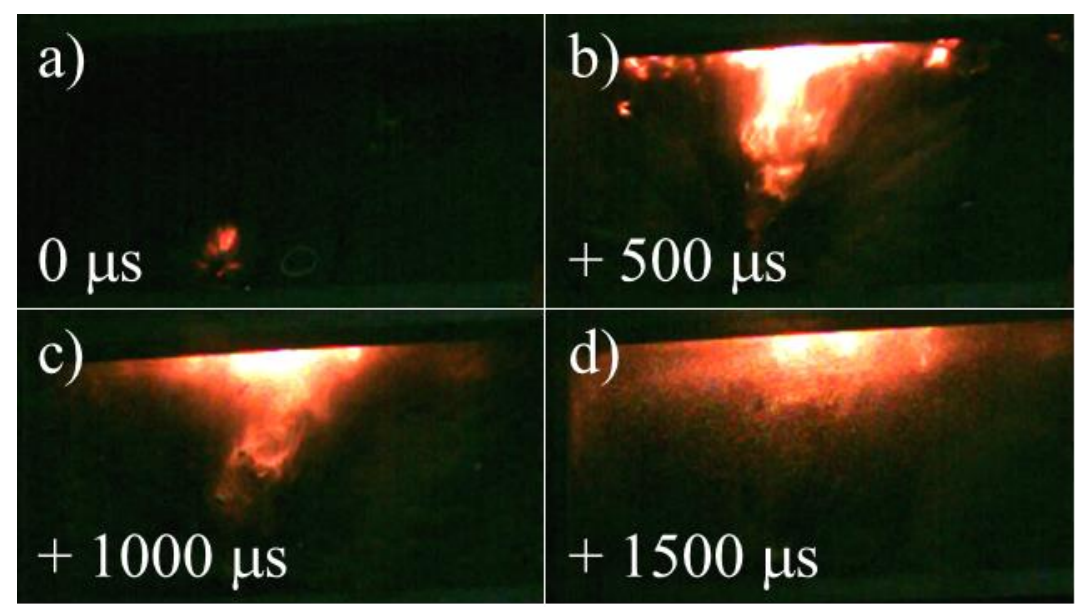

Figure 13. Time-lapse images showing the event of 0.50 caliber bullet impact, disintegration, and propagation of fragments at a) impact, b) $500 \mathrm{~ms}$ after impact, c) $1000 \mathrm{~ms}$ after impact, and d) $1500 \mathrm{~ms}$ after impact against the Corner Unit's armor panel.

The A-Frame Unit was tested using a 5-pound C4 explosive charge set on the A-Frame Unit. This test is set to simulate a small satchel-like charge placed on one of the armor panels (see Figure 11) by an adversary. Overall, the A-Frame Unit was successful in resisting the explosive threat. The front armor plate that the explosive was placed on had a hole the shape of the charge formed through it. The steel that was cut from the front armor plate impacted the bottom rear armor plate, trajectory being a result from the angle of the front armor. The essential flyer plate impacts and penetrates the lower armor plate causing debris to fly from the rear bottom armor. The damage to the front and rear armor plates is shown in Figure 14. This test result also revealed that direct line of sight or access to the asset through the damage location will be denied to the potential attacker. 


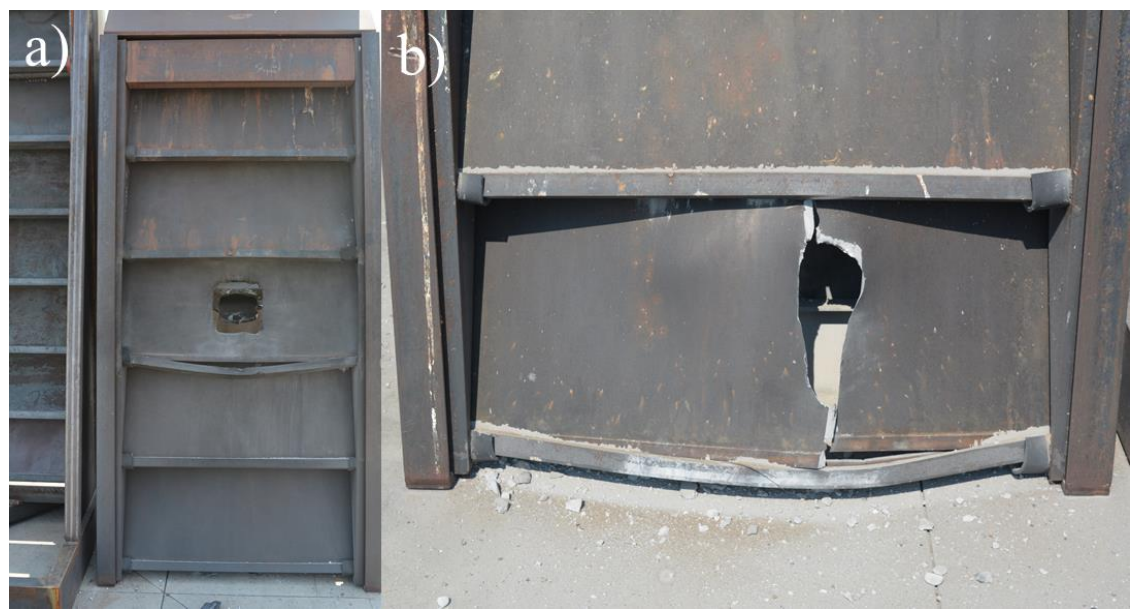

Figure 14. Pictures of A-Frame Unit post C4 charge explosion showing a) square hole formed through front armor and $b$ ) perforation through the bottom rear armor.

The explosion causes the entire unit to shift backwards $\sim 8$ " but still maintains the mated connection with the adjacent Corner Unit and the Top Hat remains on top of the lower section of the unit. The movement experienced by the A-Frame Unit could be mitigated through use of steel cabling through the adjacent A-Frame Units and/or Corner Unit to tie all units together thus distributing the load across multiple units. During the explosive event, the front armor flyer plate damage and debris is visible from the dust generated at the back of the unit. Also visible is the movement of the lower part of the A-Frame Unit while the Top Hat is inertially responding to the movement of the lower frame. However, the Top Hat remains seated in the housing of the lower section and rights itself after the lower part of the A-Frame comes to rest. A time-lapse of the macro-level response of the A-Frame Unit is shown in Figure 15.

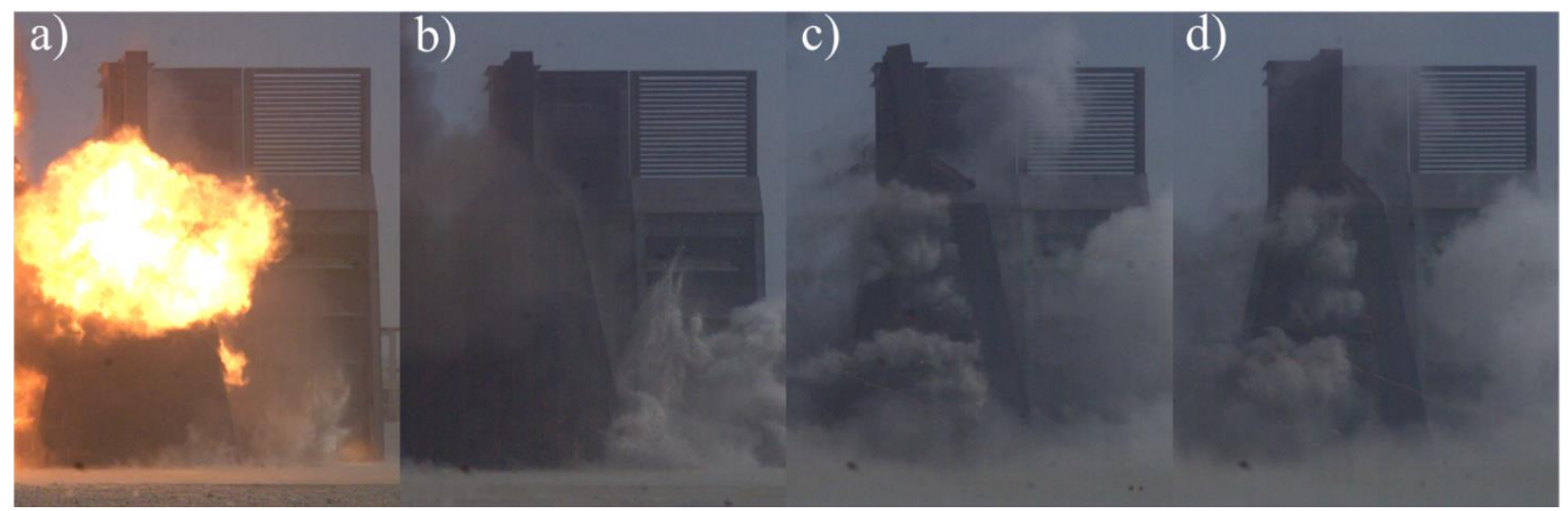

Figure 15. 5-pound C4 charge test against the A-Frame Unit illustrating a) initial blast and impact of debris behind unit, b) impact of larger debris behind unit; no movement of unit yet observed, c) movement of lower part of unit as Top Hat flexes forward, d) lower part of unit comes to rest and Top Hat returns to proper position in the unit. 


\section{Conclusions}

In 2013, the need for power transformer protection became apparent with the MetCalf attacks. In 2015 INL rose to the call to fabricate and test the first A-Frame barrier to meet this need. The project was successful in that a mobile barrier was created that could withstand UL level 10 threats. After consulting with utility industry professionals, the need for seamless $360^{\circ}$ protection arose. This TCF project succeed at answering this need.

The primary goal of this TCF project was to design, fabricate, and validate a Transformer Barrier Corner Unit with the intent of mating the Corner Unit to the existing A-Frame Barrier for $360^{\circ}$ protection for highly valuable energy generation/transmission equipment. At the Idaho National Laboratory, a prototype was designed, reviewed, fabrication by another party, and validated to prove the design of the Corner Unit. The Corner Unit and the second A-Frame Unit that was fabricated by Waltonen Engineering, Inc. were assembled by utility crews with normally available equipment without prior training or experience.

These barriers were ballistically tested with 0.50 caliber ammunition and found to pass without endangering any vital equipment beyond the barriers. The A-frame was also tested with a small 5-pound C4 charge. Although the A-Frame moved slightly when subjected to the explosion, the unit survived intact and the movement that was experienced by the unit can be easily mitigated in a full-scale system.

The Corner Unit and A-Frame system will hopefully quickly transition into a commercially viable product with the intent to sell to customers to protect vital electrical grid infrastructure around the United States. The vital infrastructure will not be visible through the Corner Unit and A-Frame Unit barrier system thus eliminating the shot line from any elementary rogue attacks. The use of the barrier system can be extrapolated to the use of temporary or frequently changing areas that require protection due to the quick construction/deconstruction of the barrier system. 


\section{Appendix A \\ Invention Disclosure Record}

1. 481.35

$01 / 26 / 2000$

2. Rev. 02 Qversion: 5

IDR/Docket \#: BA-1163
INVENTION DISCLOSURE

RECORD

(DOE Contract No. DE-AC07-

05-ID14517)
Contains Proprietary or Business

Sensitive Unclassified Information, do not disclose outside of BEA without prior proper approvals (when data supplied)

Date Submitted: 11/18/2019

1.0 Title

Transformer Barrier Corner Unit

2.0 Investigator(s)

\begin{tabular}{|l|l|l|}
\hline Name & Work Phone & Concurred \\
\hline Kenneth R Bratton & 2085260957 & $11 / 18 / 2019$ \\
\hline Teddy R Reed & 2085268425 & $12 / 4 / 2019$ \\
\hline Henry S Chu & 2085267514 & $11 / 23 / 2019$ \\
\hline Todd L Johnson & 2085264180 & $11 / 19 / 2019$ \\
\hline
\end{tabular}

2.1 Non-Employee Investigator(s)

- there are no responses in this list -

3.0 Summary

3.1 Non-Confidential Summary:

A Transformer Barrier Corner Unit was developed to protect critical infrastructure. The Corner Unit consists of 3 major parts: 1) concrete base, 2) steel rail frame, and 3) an armor panel cassette. The modular nature of the Corner Unit allows for easy construction utilizing common power utility trucks as well as easy replacement of damaged panels. This structure is designed to withstand ballistic threats exceeding UL Level 10 and crash/blast impacts. The Corner Unit mates with the existing Transformer Barrier A-Frame Unit (US Patent 10053887) to achieve full $360^{\circ}$ protection of critical infrastructure.

4.0 Narrative

4.1 Customer: Please provide a description of the customer and their unmet need. What is the problem you are solving for your customer and why is it important? Are there any specific companies or individuals that you believe would be interested in licensing your invention for commercial deployment?

The Transformer Barrier Corner Unit will provide seamless corner protection as well as a transition joint where the Transformer Barrier A-Frame lines meet. With addition of the Transformer Barrier Corner Unit, $360^{\circ}$ protection of vital equipment is possible. Currently, there is a lack of protective equipment surrounding power generation/transmission equipment currently in use and susceptible to simple rogue attacks. The problem solved for the customer is ensuring protection of the equipment that is difficult to replace due to long-lead time or one-ofa-kind pieces of equipment.

Potential customers include any power generation and/or transmission companies that have remote installations or substations. Preliminary talks have been held with the security officers and mangers of Southern Company and American Electric Company regarding 
commercialization and deployment of this invention. Another potential customer is those who desire temporary protection that can be readily assembled/disassembled in a short amount of time without need of technical training.

Waltonen Engineering Inc. has expressed interest in licensing the Corner Unit and the A-Frame structures for large-scale manufacturing.

4.2 Opportunity: What is the magnitude of the customer problem in terms of economic and/or societal impact and why hasn't it been solved before?

Some of these power generation and transfer equipment are one-of-a-kind making their replacement difficult or impossible. The attacks on the transformers at the Metcalf substation resulted in \$15M in damages and could have affected thousands via loss of power had the attacks been during the summer (higher peak electrical usage). A federal Reliability Standard (CIP-014-2), FERC published in 2015, mandates that Transmission stations, substations, and control centers should be protected.

Fence-type barriers are not viable solutions due to the costs of driving anchor points as well as setting the internal ribs for the armor plates. The construction cost of these fence-type barriers to fully secure the perimeter of the substation are prohibitively expensive leaving the market open for a more economically and manpower efficient barrier. Additionally, these barriers are only effective up to a UL level of 5 ballistic protection.

4.3 Solution: What's your solution for satisfying the identified need and seizing the opportunity? What are the key features and functions, inputs and outputs? Please provide a description of the invention background and how the invention originated along with the novel elements of your approach.

The freestanding Corner Unit does not require the anchor points or rib installation that fencetype barriers do. This feature dramatically reduces the cost, both fiscally and manpower, of installation making the Corner Unit more feasible for potential customers. The market for simple installation, modular, freestanding, and ballistic ratings up to UL level 10 threats is very promising.

The key features of the Corner Unit are its ease of construction/deconstruction, modular nature, freestanding structure, and ballistic rating up to UL level 10 threats. The ease of construction allows for the rapid deployment, compared to fence-type barriers, of the Corner Unit. True to its modular nature, to construct the Corner Unit first the frame is erected, concrete is poured into the base form, and armor panels are inserted. The modular nature also allows for the replacement or downsizing of armor plates according to anticipated threat level or capitaldriven design. The freestanding design reduces the cost of installation and deployment allowing the Corner Unit to be deployed and redeployed without expensive umbilical equipment (ribs and anchors). The existing product on the market is designed to mitigate up to a UL level 5 threat (one shot from a 308 caliber rifle round). The Corner Unit will be deployed with armor plate rated at a UL level 10 threat allowing the Corner Unit to perform at a significantly higher level.

The invention originated from a customer request for a unit to protect the transition points between lines of the Transformer Barrier A-Frame Unit and to mate with the existing A-Frame Units. The Corner Unit achieves this goal by seamlessly mating with existing A-Frame structures providing full $360^{\circ}$ coverage and completely blocking the shot-line of potential threats. The Corner Unit's design is heavily influenced by the successful design of the A-Frame design in that a similar armor plate design and orientation are employed to achieve a high level of performance. However, where the Corner Unit differs in design from the A-Frame is in the single armor stack design. During A-Frame ballistic testing, it was observed that the front armor held 
against up to UL level 10 threats leaving the rear armor perfectly intact. To reduce cost, the armor design was reduced to include only the front armor plating and to extend this armor plating the full height of the A-Frame to simplify construction further.

4.4 Team: What additional people/institutions/companies are needed to ensure successful validation or implementation of your solution (i.e. what skills or expertise do you need to address the technical barriers of your solution)?

There are no known technical barriers impeding the Corner Unit production. Waltonen Engineering Inc. has expressed interest in licensing the A-Frame and Corner Unit for production at market scale. Waltonen has also expressed interest in constructing one Corner Unit and one A-Frame Unit as well as produce manufacturing grade drawings for rapid shift into fabrication.

4.5 Advantage: What is your "unfair" advantage over the alternatives? How competitive is the space and what other companies / institutions are developing solutions to address the customer problem? How does your solution perform significantly better than alternatives? What are the elements of the invention ensuring your solution advances the field or compares favorably with the latest state of the art or current practice?

The Corner Unit has an unfair advantage over other barrier systems through its ease of construction/deconstruction, modular nature, freestanding structure, and ballistic rating up to UL level 10 threats. The Corner Unit can be constructed using standard industrial processes and use commercial "of-the-shelf" materials thus reducing cost. The modular nature of the Corner Unit provides the advantage of easily replacing damaged plates or changing the thickness of the armor plates depending on the requirements of protection or capital-driven designs.

Additionally, the modular nature allows simple deconstruction of the barrier system, without technical training, into smaller parts which then can be easily transported to a new location. The benefit of a transportable barrier system is realized in the reduction of resources and manpower needed, if not the innate ability, to install/relocate a Corner Unit system over a competitor's fence-type foundation and mounting system. These fence-type barriers require deep pier footing and strong anchoring points to both support the height of the ballistic fence against wind and blast pressure loads. Conversely, the Corner Unit requires no anchors, as it is freestanding, and does not require any specialty lifting equipment outside of normal power utility boom trucks to install. The ballistic performance of the Corner Unit is dramatically superior to existing UL level 5 threat mitigation of the competition.

4.6 Results: What results will be achieved if your solution is successfully applied? What are the quantifiable benefits to the customer and estimated returns to your lab? How do partners and key stakeholders (customers, industries, etc.) benefit in tangible and intangible ways? The Corner Unit and A-Frame system will quickly transition into a commercially viable product and intent to sell to customers to protect vital infrastructure around the United States. The vital infrastructure will not be visible through the Corner Unit and A-Frame Unit barrier system thus eliminating the shot line from any elementary rogue attacks. The use of the barrier system can be extrapolated to the use of temporary or frequently changing areas that require protection due to the quick construction/deconstruction of the barrier system.

Through the licensure process the Laboratory will earn royalties from the production companies. Industry partner will benefit due to the open market of the barrier system will have a good-selling product to add to their sales while the customer saves on potentially millions of dollars in damages to vital equipment.

4.7 Additional details describing the invention: Include experimental details and work done to demonstrate the invention that have not be described above. 
Ballistic verification testing will be conducted at the National Security Test Range (NSTR) to ensure the Corner Unit's ability to mitigate UL level 10 threats.

4.8 Please describe the contribution of each PI listed in section 2.

- no value provided -

5.0 Mission Alignment

5.1 Please select the directorate that most closely aligns with your disclosure:

National \& Homeland Security

5.2 Please identify relevant "Core Capability" categories as defined by DOE.

Mechanical Design and Engineering

6.0 Readiness Level

6.1 What is the Level of Development (Technology Readiness Level)?

TRL 7 Full-scale, similar (prototypical) system demonstrated in a relevant environment

6.2 Provide additional information relative to development status:

- no value provided -

7.0 Public Releases

7.0.1 Has a publication or presentation of this material occurred?

No

7.0.1.1 If Yes, provide name of publication or presentation

- no value provided -

7.0.2 Is a future publication or presentation planned?

No

7.0.2.1 If Yes, provide the date and description of all planned publications, oral presentations, poster sessions, or other public dissemination of the invention:

- no value provided -

7.0.3 Has the invention been sold or offered for sale?

No

7.0.3.1 If Yes, indicated the date of first sale or offer for sale.

- no value provided -

7.0.4 Has a patent search by the inventors been performed?

No

7.0.4.1 If yes, indicate date: - no value provided -

7.0.4.2 If yes, provide a conclusion of patent search. Please attach your findings to this IDR. - no value provided -

7.0.5 Has a literature search by the inventors been performed?

No

7.0.5.1 If yes, indicate date:

- no value provided -

7.0.5.2 If yes, describe conclusion of literature search. Please attach your findings to this IDR.

- no value provided -

7.1 Publications

- there are no responses in this list -

8.0 Class Waiver

8.1 Does this invention relate to the storage and disposal of civilian high-level nuclear waste and spent fuel technology?

No

8.2 Is this invention related to a national security technology, considered to be classified or sensitive under the Atomic Energy Act? 
No

8.3 Was the research that led to this discovery funded in part or entirely by the United States Department of Energy Steel Initiative or Metals Initiative?

No

8.4 Was the research that led to this discovery funded in part or entirely by the United States Advanced Battery Consortium research and development?

No

8.5 Was the research that led to this discovery funded in part or entirely by Electric Power Research Institute (EPRI) or the Gas Research Institute (GRI)?

No

8.6 Is research covered by an international treaty or agreement of the United States Government? No

8.6.1 If Yes, indicate agreement:

- no value provided -

8.7 Was the research that led to this discovery funded in part or entirely by the United States Department of Energy weapons program?

No

9.0 Funding Questions

9.0.1 Is the content of this IDR outside the scope of work related to the mission of the INL? No

9.0.2 Is further Government funding anticipated?

No

9.0.3 Was this IDR conceived or developed while charging/working on an LDRD? No

9.0.3.1 If Yes, what is/are the LDRD project number \#\#-\#\#\#\#

- no value provided -

9.0.4 Was this IDR conceived or developed while working on a Strategic Partnerships Project (formerly WFO)?

No

9.0.4.1 If Yes, what is/are the Project No(s)?

- no value provided -

9.0.5 Was this IDR conceived or developed while working on a CRADA (Cooperative Research and Development Agreement?

No

9.0.5.1 If Yes, state CRADA partner and CRADA number.

- no value provided -

9.0.6 Agreement to Commercialize Technology (ACT)? No

9.0.6.1 If yes, identify agreement number: - no value provided -

9.0.7 Was this IDR conceived or developed while working under a Joint Appointment Agreement (JAA)

No

9.0.7.1 Please identify who the JAA was with and when the JAA took place.

- no value provided -

9.0.8 Did this invention arise from Department of Homeland Security (DHS) funding? No

9.0.8.1 Please identify DHS funding source: 
- no value provided -

9.0.9 Was the development of this invention funded under a consortia or institute? Examples include: Critical Materials Institute (CMI), LightMAT, CES-21, ChemCatBio, HydroGen, RAPID or CyberPARC.

No

9.0.9.1 If yes, please identify the consortia or institute.

- no value provided -

9.1 Funding Sources - the sum of all sources must equal 100

\begin{tabular}{|l|l|l|l|}
\hline Charge Number & Amount & B\&R Code: & B\&R Description: \\
\hline 103438 & 100 & TE1101000 & Transmission Reliability \& Renewables Integration \\
\hline
\end{tabular}

10.0 Attachments

- there are no responses in this list 


\title{
Appendix B Waltonen Proposal Package
}

\section{TRANSFORMER BARRIER CORNER PROTOTYPE FABRICATION}

\author{
REQUEST FOR PROPOSAL: 2882740
}

\section{PROPOSAL}

PREPARED FOR:

Idaho National Laboratories

Mr. Brett Horsburgh

Lead Contract Specialist 2525 Fremont Ave.

Idaho Falls ID 83402

brett.horsburgh@inl.gov

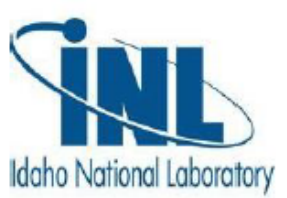

PREPARED BY

Waltonen Engineering, Inc.

31330 Mound Rd.

Warren, Michigan 48092

Phone: (586) 274-2300

Fax: (586) 274-2330

03 FEBRUARY 2020

\begin{abstract}
This proposal includes data that shall not be disclosed outside the U. S. Govemment and shall not be duplicated, used, or disclosed - in whole or in part - for any purpose other than to evaluate this proposal. If. however, a contract is awarded to this offeror as a result of - or in connection with - the submission of this data, U. S. Government the shall have the right to duplicate, use, or disclose the data to the extent provided in the resulting contract. This restriction does not limit U.S. Government's right to use information contained in this data if obtained from another
\end{abstract} source without restriction. The data subject to this restriction are contained in all pages of this proposal. 


\section{TABLE OF CONTENTS}

List of Figures...................................................................................................................... iv

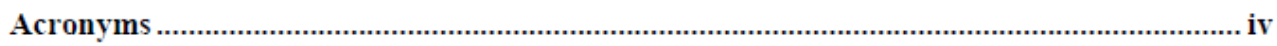

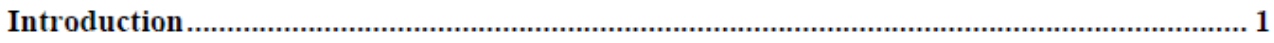

Demonstrated Corporate Experience ………………...................................................... 3

Past Performance ............................................................................................................... 4

Combat Vehicle Armor Technology Objective …………………………........................... 4

GVSC Test Fixtures for the Blast Analytical Test System (BATS) …….............................. 4

Bell 505 Helicopter Assembly Line...........................................................................

Proposal Submittal Requirements (RFP 3.) .................................................................. 5

Proposal/Certification Form PROC-2120 (3.3.1) ………………………………...

Waltonen Point of Contact (3.3.2) .........................................................................

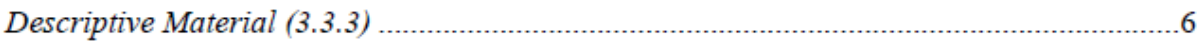

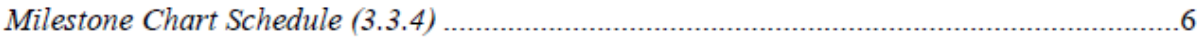

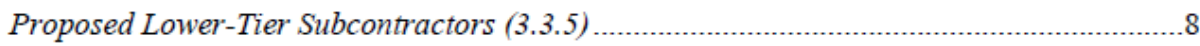

Socioeconomic Classification (RFP 4.) …………………................................................ 8

Proposal Instructions (RFP 6.) ............................................................................................ 8

Interpretations and Exceptions (6.1) ......................................................................

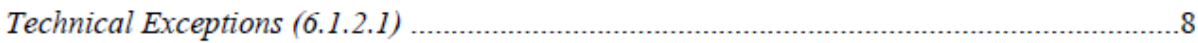

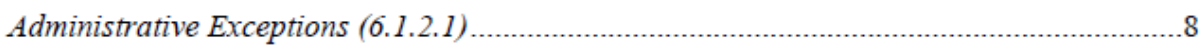

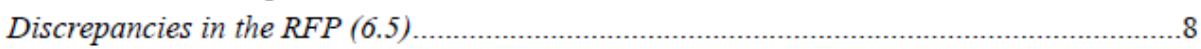

Brand Name or Equal (6.6) ....................................................................................

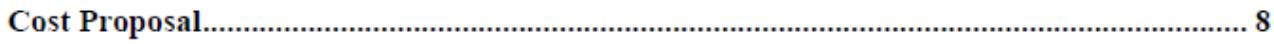

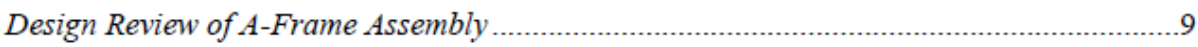

Design Review of Corner Unit .............................................................................

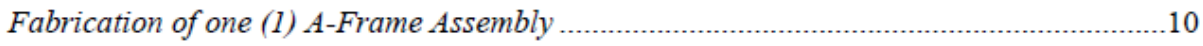

Fabrication of one (1) Corner Unit Assembly …………………............................10

Fabrication of one (1) A-Frame Replacement Cassette …............................................10

Fabrication of one (1) Corner Unit Replacement Cassette …......................................10

Delivery of Fabricated Parts to INL .........................................................................10

Cost Estimate for Production Units (A-Frame and Corner Unit) Per SPC, Section 6 .........10

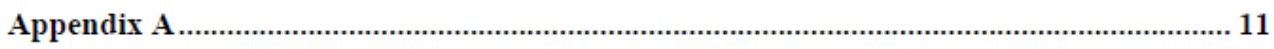

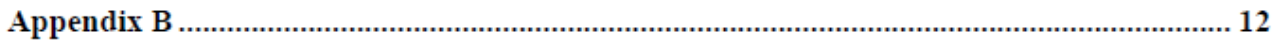

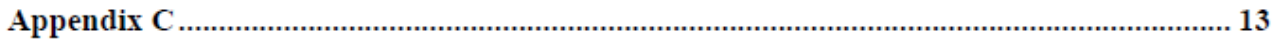

Use or disclosure of proposal data is subject to the restrictions on the title page of this proposal. ii of $\mathrm{V}$

Waltonen Engineering, Inc. $\quad 03$ February 2020

Proposal 
RFP 2882740

Proposal

\section{V'WALTONEN}

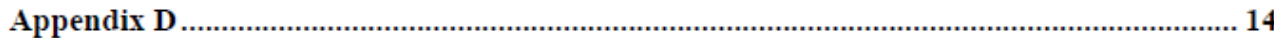

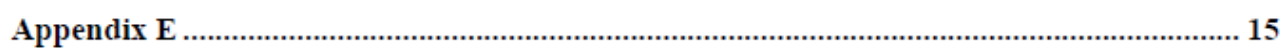

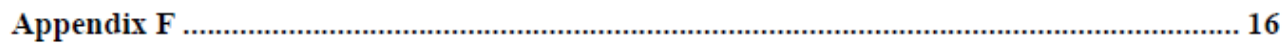

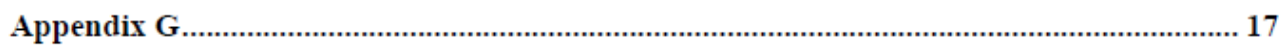

Use or disclosure of proposal data is subject to the restrictions on the title page of this proposal. 


\section{LIST OF FIGURES}

Figure 1: Waltonen HQ...... 1

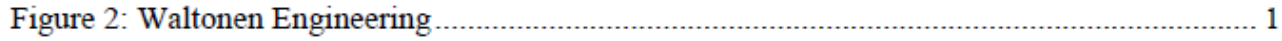

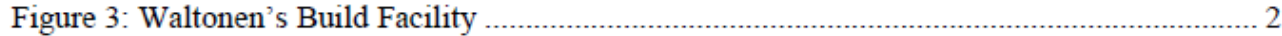

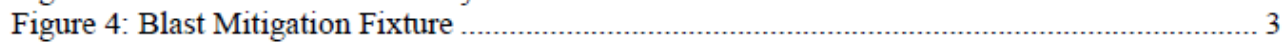

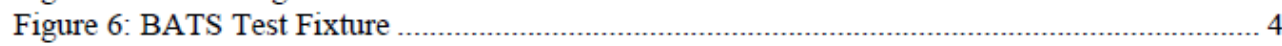

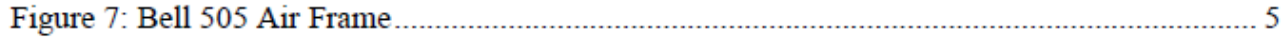

Figure 8: Bell 505 Assembly Tool ..................................................................................... 5

\section{ACRONYMS}

\begin{tabular}{|l|l|}
\hline BOM & Bill of Material \\
\hline CAD & Computer Aided Design \\
\hline CAE & Computer Aided Engineering \\
\hline CDRL & Contract Data Requirements List \\
\hline COTS & Coordinated Measuring Machine \\
\hline DCAA & Defense Contract Audit Agency \\
\hline DCMA & Defense Contract Management Agency \\
\hline FCL & Facility Clearance \\
\hline FEA & Finite Effects Analysis \\
\hline FOB & Freight Out Bound \\
\hline GD\&T & Geometric Dimension and Tolerance \\
\hline GFE & Government Furnished Equipment \\
\hline GSPEL & Ground System Power \& Energy Lab \\
\hline GVSC & Ground Vehicle Systems Center \\
\hline INL & Idaho National Laboratories \\
\hline JLTV & Joint Light Tactical Vehicle \\
\hline KBS & Knowledge Based Services \\
\hline LAV & Light Amphibious Vehicle \\
\hline LTATV & Light Tactical All-Terrain Vehicle \\
\hline M\&S & Modeling and Simulation \\
\hline MRAP & Mine Resistant Ambush Protection \\
\hline NAICS & North American Industry Classification System \\
\hline NC & Numerical Control \\
\hline PO & Purchase Order \\
\hline R\&D & Research and Development \\
\hline RFP & Request for Proposal \\
\hline
\end{tabular}

Use or disclosure of proposal data is subject to the restrictions on the title page of this proposal. 
RFP 2882740

Proposal

\section{V'WALtonen}

\begin{tabular}{|l|l|}
\hline SBA & Small Business Association \\
\hline SB & Small Business \\
\hline SITREP & Situation Reports \\
\hline SOCOM & Special Operations Command \\
\hline SOW & Statement of Work \\
\hline TACOM & Tank Automotive Command \\
\hline TARDEC & Tank Automotive Research Development and Engineering center \\
\hline TDP & Technical Data Package \\
\hline TO & Task Order \\
\hline VSA & Variation Simulation Analysis \\
\hline WBS & Work Breakdown Structure \\
\hline
\end{tabular}




\section{Proposal}

\section{INTRODUCTION}

Waltonen Engineering, Inc., (Waltonen) submits this proposal to Idaho National Laboratories (INL) Request for Proposal (RFP) \# 288270 for the Transformer Barrier Prototype Fabrication.

Waltonen is a Michigan based small business under various NAICS codes including 332999 . We specialize in engineering, design, systems engineering, prototype and production manufacturing. We have an office in Warren, Michigan with a SECRET Facility Clearance (FCL), and a build facility in Troy, Michigan.

Founded in 1957, Waltonen is a leader in engineering and design services. Waltonen is an ISO 9001:2015 certified company with extensive experience in product design, manufacturing, quality, engineering, test systems, and program management with various government and commercial customers. Waltonen has firsthand experience with nontraditional approaches, allowing us to maintain our market leadership with a multi-industry customer base. We support the defense, automotive, aerospace, transportation, heavy equipment, medical device, and consumer markets.

Waltonen has over 300 seats of various $\mathrm{CAD}, \mathrm{CAE}$, and CAM software, including Pro-E Wildfire, Pro/Cable, Pro/AAX, Siemens NX, TeamCenter CATIA, and Solidworks that our more than 150 scientists, engineers, and designers use to meet our customers' needs. Our designers and engineers are cross-trained in house on multiple CAD software packages so that they can easily work on different programs, and our IT specialists are experienced in all forms of hardware and software.

Our staff is trained in multiple disciplines of engineering including:

- Product Design

- Geometric Dimensioning and Tolerancing (GD\&T)

- Modeling and Simulation (M\&S)

- Variation Simulation Analysis (VSA)

- Manufacturing Engineering

- Tool Design

- Plant Layout

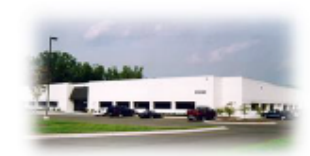

- Manufacturing Processing

As a small business Prime Contractor, we hold Indefinite Delivery Indefinite Quantity (IDIQ) contracts for the U.S. Government including:

- Tank Automotive Command (TACOM) Strategic Service Solutions (TS3) Knowledge Based Services (KBS) portfolio W56HZV-15-D-KB27 for engineering and technical services

Use or disclosure of proposal data is subject to the restrictions on the title page of this proposal. 1 of 19 
- TS3 Research and Development (R\&D) portfolio W56HZV-15-D-RD19 for research and development technical support

Waltonen has been awarded thirteen (13) TO's on past and present IDIQ contracts, we use the teaming approach to fulfill the requirements of these TOs. The subcontractors consist of large businesses, small business and universities. As the prime integrator and program manager lead, Waltonen submits the Situation Reports (SITREP), facilitates the design reviews and program meetings, fulfills all of the Contract Data Requirements Lists (CDRL) requirements and manages all of the program cost and schedule requirements. All of the TOs were successfully completed,

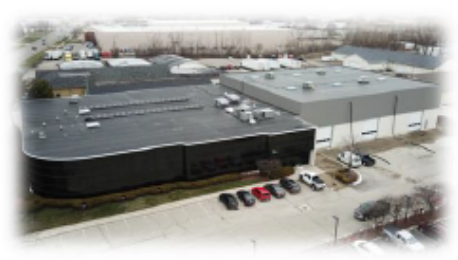

FIGURE 3: WALTONEN'S BUILD FACILITY meeting all contract deliverables.

Waltonen's build facility is an ISO 9001:2015 and AS9100 certified tooling company that supports the aerospace, automotive and defense industries with prototype fabrication, assembly tooling, checking fixtures and gauges, composite tooling, fixtures and jigs. The building has over 60,000 square feet of machining space, offices, and assembly areas. This includes three (3) large bays with over 20,000 square feet of assembly area and three (3) ten ton overhead cranes. They have extensive experience with large weldments, machining, floor assembly jigs, assembly fixtures, master gages and drill and trim fixtures.

Our list of equipment includes:

- Tarus 3+2 high speed milling machine

- Chevalier FVM 3016-DCL Milling Center

- Chevalier EM1620L Milling Center

- Chevalier EM2040L Milling Center

- DeVlieg Boring Mill

- Two (2) Coordinated Measuring Machines (CMM)

- Two API Laser Trackers

Waltonen has the equipment personnel, quality systems and floor space to support the all aspects of fabrication. This includes Numerical Control (NC) programming, surface development, mock up prototype development, and metrology.

Waltonen has the people, processes and past performance to meet all of the objectives for the transformer barrier prototype fabrication for INL. 


\section{DEMONSTRATED CORPORATE EXPERIENCE}

Waltonen has extensive experience in the design and fabrication of large fixtures and assemblies for both government and commercial customers.

Military Vehicle Design and Fabrication

Waltonen has supplied the Ground Vehicle Systems Center (GVSC) previously known as TARDEC with design and build services for numerous combat vehicle programs. Some of the programs include the Husky, Cougar, Combat Boat, Special Operations Command (SOCOM) Light Tactical All-Terrain Vehicle (LTATV), Bradley, Mine Resistant Ambush Protection (MRAP) and Light Amphibious Vehicle (LAV-25) programs. Since 2000, we have ongoing contracts with military prime contractors for military programs including Abrams, MRAP, Joint Light Tactical Vehicle (JLTV), HMMWV, and Stryker.

For the GVSC Laboratories we have designed numerous test fixtures for durability and product evaluation testing. These include wheel hub adapters, blast impact, spindle arm, tire-wheel separator, and armor attachment vibration fixtures.

We developed, designed and fabricated blast mitigation vehicle floors and hulls and the associated test fixtures required for live testing

\section{Commercial Tooling Design and Build}

Waltonen provides the transportation and aerospace markets with tooling design and fabrication. Many of these systems are large complete assembly lines requiring simultaneous

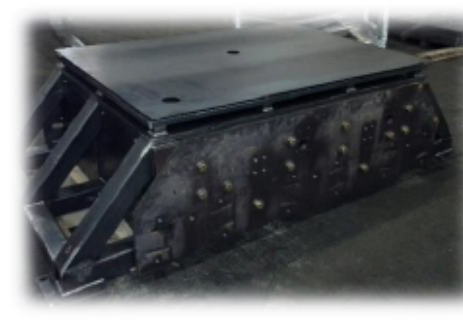

FIGURE 4: BLAST MIIGATION FDTURE engineering with design, processing and Modeling and Simulation (M\&S). For General Motors we develop automated underbody welding systems, material handling and robotic assembly cells. We have provided John Deere with welding fixtures, and for Bell Helicopter we designed developed, fabricated and installed the assembly line for the 505 Bell Helicopter.

\section{Computer Aided Design/Engineering}

Our software includes over 80 seats Pro-E Wildfire, Pro/Cable, Pro/AAX, over 200 seats Siemens NX including the full Tecnomatix suite of software, and various other software packages including CATIA, Solidworks and Solid Edge. We have over 300 workstations that our designers and engineers use to support our diverse customer and market base. Our designers and engineers are cross-trained in house on multiple CAD software packages so they can easily work on different programs, and our IT specialists are experienced in all forms of hardware and software. 


\section{PAST PERFORMANCE}

Waltonen has extensive experience in designing and fabricating large weldments and assemblies. We are proud to present the following past performances that are relevant to the RFP 2882740

\section{COMBAT VEHICLE ARMOR TECHNOLOGY OBJECTIVE}

Waltonen designed and managed production of a ballistic and vibration test fixture to represent a rear quarter of a proposed armored vehicle frame. In addition to the fixture, Waltonen engineers designed removable and interchangeable stands to attach the fixture to a vibration plate or other precision mounting surface. This project included the creation of fourteen separate concepts for attaching armor to the fixture or to other armor plates, or assemblies. Several combinations of these concepts were selected for full design, development, analysis, and manufacture. Waltonen selected and specified all the purchased

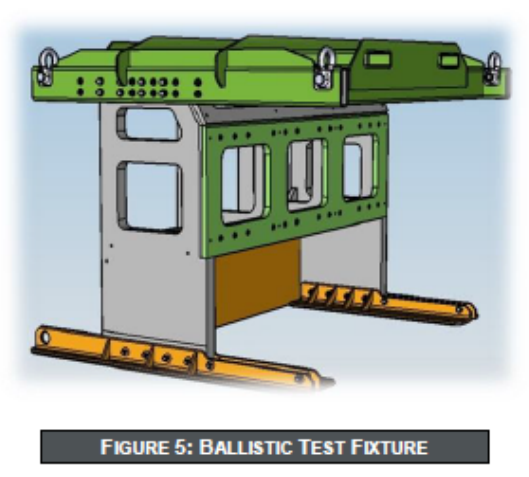
hardware components and build materials. We defined the assembly, welding, and finish specifications and processes. The project involved multiple mechanical parts and their material specifications. We created 3D CAD models, complete assembly drawings, a full Bill of Materials (BOM), and all of the individual detail drawings. Waltonen provided this data in a number of formats (Pro-E models and drawings, parasolids, pdf models, and pdf drawings). We documented the material specifications, finishes/coatings, and test requirements in the Level III TDP package. All Commercial-Off-the-Shelf (COTS) items were identified and specified with $\mathrm{MIL}$ grades.

This contract is directly relevant in that we completed the engineering design, analysis, documentation, and Level III TDP for a ballistic and vibration armor attachment test fixture. We validated the model and metadata accuracy in compliance with the ASME standards. Waltonen specified all purchased hardware components and managed the build of the welded assemblies.

\section{GVSC TEST FIXTURES FOR THE BLAST ANALYTICAL TEST SYSTEM (BATS)}

Waltonen was contracted by the GVSC Ground System Power \& Energy Lab (GSPEL) to design, engineer, and fabricate Impact test fixtures for the BATS hydraulic blast test. Working with GVSC requirements, Waltonen engineers designed the structures to withstand $300 \mathrm{~g}$ of force and vibration frequency of $200 \mathrm{~Hz}$. Multiple Finite Effects Analysis (FEA) were performed to optimize the design to meet the requirements. With the design complete, Waltonen fabricated the test fixtures including welding, milling,

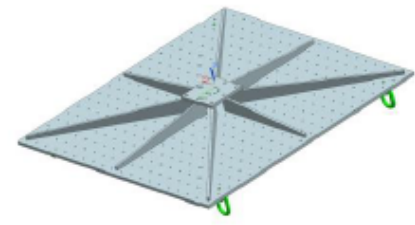

Use or disclosure of proposal data is subject to the restrictions on the title page of this proposal. Waltonen Engineering, Inc. 
Blanchard grinding, and black oxide coating. The large 2 meter by 2 meter test fixture was designed and fabricated within 12 weeks timing.

This contract is directly relevant in that we completed the engineering design, of a large and heavy fixture that included welding, milling and grinding.

\section{BELL 505 HELICOPTER ASSEMBLY LINE}

Waltonen was contracted under multiple orders to engineer, design and fabricate an assembly line for the Bell 505 helicopter. Bell assigned their internal 505 engineering team the development of a more efficient way to manufacture a commercial aircraft at a competitive price. The team developed an unproven bolt together design. Waltonen engineers used M\&S to demonstrate the design feasibility of the bolt together concept, along with development of prototype build tooling.

Bell successfully assembled airworthy aircraft and performed all necessary testing on the prototype systems.

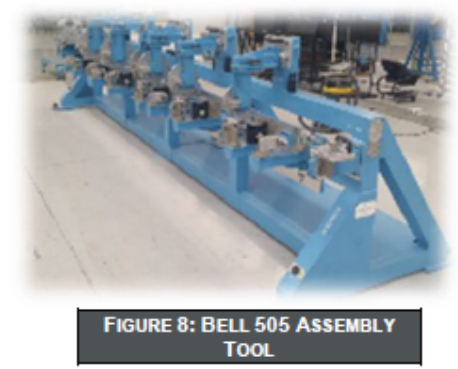

8: BELL 505
With the approved product design, Waltonen developed the production tooling for the saleable units. We were able to reuse many components in the prototype tooling, reducing capital investment.

Waltonen fabricated over 100 production assembly tools, validated each tool at our ITS facility, and installed the fixtures in multiple locations. Using laser trackers, we revalidated the tooling at the Bell production plants to insure proper quality control.

This contract is directly relevant to RFP 2882740 as it shows Waltonen's capabilities to design, fabricate and validate large complex systems, under tight timing and costs constraints.

\section{PROPOSAL SUBMITTAL REQUIREMENTS (RFP 3.)}

Waltonen has reviewed all of the documents and can meet all requirements as spelled out in the Specification SPC-2758 Rev. 01 Transformer Barrier Corner Unit, RFP NO 2882740, INL Form 2120 Proposal Certification Form for RFP No. 2882740, and INL Form 1811 Draft Contract no 2882740.

\section{PROPOSAL/CERTIFICATION FORM PROC-2120 (3.3.1)}

The completed PROC-210 can be found in in the attached pdf. Document titled: PROC-2120 Waltonen RFP 2882740. The price is FOB Destination, and we have quoted the shipping charges on a separate line item.

Waltonen is registered in the INL Portal, and our SAM registration is current and up to date. 


\section{WALTONEN POINT OF CONTACT (3.3.2)}

The point of contact for this proposal will be:

Thomas Laboda, Director, Business Development Thomas.laboda@waltonen.com

586-274-2336

\section{DESCRIPTIVE MATERIAL (3.3.3)}

For the build of the transformer barrier units, Waltonen will not be purchasing COTS items. The material for the fabrication will be purchased from approved steel suppliers. All armor plating will have the required material testing approvals.

\section{MILESTONE CHART SCHEDULE (3.3.4)}

Waltonen has extensive experience in managing large complex programs for a multitude of customers from diverse market perspectives. We use Microsoft Project to manage the timing of our programs. Please refer to Appendix A for a preliminary timing and project plan for the transformer barrier program. A final project plan will be developed during the Kick Off Meeting.

For the design review of the A-Frame and Corner Unit, the timing will be four (4) to six (6) weeks after program kick off. Both designs will be reviewed simultaneously.

For the fabrication of the two units, and replacement cartridges, the timing will be eleven (11) to twelve (12) weeks.

The Work Breakdown Structure (WBS) for a design and build program consists of numerous steps that work in parallel and sequentially to meet the program requirement. The WBS for equipment fabrication, assembly, and shipping has the following steps:

1) Program kick off

a. Validate requirements with customer

i. Establish design guidelines

ii. Acquire design templates for title blocks, formatting etc.

iii. Coordinate customer material specifications

b. Start design and modeling of assembly

2) $40 \%$ Design approval of completed models

a. Customer approves models for final release

b. Send approved models fabrication

c. Begin final drawings

i. Develop Preliminary Bill of Material (BOM)

ii. Individual details

iii. Sub system layout

iv. System layouts

d. Start checking drawings for final release

e. Send Preliminary BOM to fabrication

f. Identify and authorize ordering any long lead items

Use or disclosure of proposal data is subject to the restrictions on the title page of this proposal 
3) Final Design Approval

a. Customer approves final design

b. Final BOM is released to fabricator

c. All drawings and models are released to the fabricator

4) Equipment build

a. Drawings are released to the build shop

b. Program build timing is set

c. BOM is reviewed

i. Reviewed for make components or purchase components

ii. Commercial items are separated and sent to purchasing for ordering

iii. Make components are sent to fabrication for review

d. Fabrication

i. Drawings are reviewed for manufacturing processes

ii. Fabrication and welding are completed to requirements

e. Machining of make components

i. Drawings are reviewed for machining requirements

ii. Machine times are scheduled per timing plan

iii. CNC Machine programs are developed and completed for applicable machines

iv. Machining

1. Milling

2. Boring

3. Lathe

f. Certification

i. All make components that require certification are sent the CMM for verification

ii. Any parts out of specification are repaired or remade

g. Assembly

i. All make and purchased components are compiled, recorded and scheduled for assembly

ii. Subassemblies are built first and evaluated for functionality

iii. Final mechanical assembly completed to the system layout drawings

h. Customer final approval in-house

1. With final approval, machine is prepped for shipping

ii. Shipping preparation

1. All parts components are marked and tagged for disassembly

2. Write reassembly plan

3. Build Support structures for heavy or fragile components

4. Attach sub assembles to pallets

5. Build crates for subassemblies

6. Gather all loose components into crates

7. Ship machine

iii. Customer Plant Rebuild

1. Reassemble equipment

2. Verify no changes to assembly 
PROPOSED LOWER-TIER SUBCONTRACTORS (3.3.5)

Waltonen intends to perform all welding and fabrication of the transformer barriers in house. We will be using an outside vendor to validate the material hardness of the armor plate. The source has not been chosen at this time, but will review the source with INL for approval.

\section{SOCIOECONOMIC CLASSIFICATION (RFP 4.)}

Waltonen is a Small Business (SB) per the requirements of NAICS Code 332999. We have approximately 150 employees which is under the threshold requirement of 750 employees.

\section{PROPOSAL INSTRUCTIONS (RFP 6.)}

\section{INTERPRETATIONS AND EXCEPTIONS (6.1)}

Waltonen has reviewed the RFP and specifications and has the following exceptions:

\section{TECHNICAL EXCEPTIONS (6.1.2.1)}

The drawings for the corner unit state in the parts list for the armor plate "1/2" High Hardness Steel Plate, by others". We provided costs for both armor plate provided by others, and provided by Waltonen.

The corner unit stated to "fill base with 8 " thick 4000 psi concrete". We did not quote the concrete. We assume this is for assembly at the site.

ADMINISTRATIVE EXCEPTIONS (6.1.2.1)

Waltonen proposes the following payment terms:

Fifty (50\%) Percent upon award, and Net 30 for final payment

DISCREPANCIES IN THE RFP (6.5)

Waltonen does not have any discrepancies with the RFP 2882740

BRAND NAME OR EQUAL (6.6)

Waltonen will not be using brand items in the fabrication of the transformer barrier units. All steel will be supplied with the proper certifications.

\section{COST PROPOSAL}

Supporting both the commercial and U.S. Government (USG) markets, Waltonen has consistently provided costs that are fair and reasonable for our services delivered in a highly competitive market. With over sixty (60) years of commercial contract and twenty (20) years of USG contract experience, we are able to provide a real world cost analysis.

As a Small Business Prime Contractor with the USG, the Defense Contract Audit Agency (DCAA) has audited and approved our accounting policies and procedures, which support our overhead and labor rates. Additionally, the Defense Contract Management Agency (DCMA) has approved our policies and procedures for the handling of Government Furnished Equipment

Use or disclosure of proposal data is subject to the restrictions on the title page of this proposal. Waltonen Engineering, Inc. 
(GFE) and the Small Business Association (SBA) performed an audit, reviewed our accounting practices, and awarded a Certificate of Competency to Waltonen. Using our audited and approved systems, Waltonen provides a Cost Proposal that is reasonably priced, competitive and supportable.

\section{DESIGN REVIEW OF A-FRAME ASSEMBLY}

Waltonen has reviewed the provided drawings for the A-Frame unit and have found them at a completed status. We will do a manufacturing optimization study, along with a study to reduce components and costs. We will investigate:

- Hinge and pin design for a collapsible unit

- Bolt together design versus welded

- Replacement of $\mathrm{C}$ channel to remove milling

- Other potential material and design savings

The hourly rates for the labor categories are fully burdened. The costs to perform this design review are:

\begin{tabular}{|l|r|r|r|}
\hline Labor Category & \multicolumn{1}{|l|}{ Rate } & \multicolumn{1}{l|}{ Hours } & \multicolumn{1}{l|}{ Total } \\
\hline CAD Designer & $\$ 75.00$ & 100 & $\$ 7,500.00$ \\
\hline Mech. Engineer & $\$ 110.00$ & 20 & $\$ 2,200.00$ \\
\hline Project Manager & $\$ 125.00$ & 20 & $\$ 2,500.00$ \\
\hline & & TOTAL & $\$ 12,200.00$ \\
\hline
\end{tabular}

\section{DESIGN REVIEW OF CORNER UNIT}

Waltonen has reviewed the provided drawings for the corner unit and have found them at approximately $75 \%$ completed status. We will complete the drawings and perform a manufacturing optimization study, along with a study to reduce components and costs. We will investigate:

- Hinge and pin design for a collapsible unit

- Bolt together design versus welded

- Replacement of C channel to remove milling

- Other potential material and design savings

The hourly rates for the labor categories are fully burdened. The costs to perform this design review are

\begin{tabular}{|l|r|r|r|}
\hline Labor Category & \multicolumn{1}{|l|}{ Rate } & \multicolumn{1}{l|}{ Hours } & \multicolumn{1}{l|}{ Total } \\
\hline CAD Designer & $\$ 75.00$ & 150 & $\$ 11,250.00$ \\
\hline Mech. Engineer & $\$ 110.00$ & 40 & $\$ 4,400.00$ \\
\hline Project Manager & $\$ 125.00$ & 30 & $\$ 3,750.00$ \\
\hline & & TOTAL & $\$ 19,400.00$ \\
\hline
\end{tabular}


FABRICATION OF ONE (1) A-FRAME ASSEMBLY

The complete breakdown and cost for the fabrication of one (1) A-Frame Unit can be found in Appendix B. We included the costs for the CNC programming and processing. This is a onetime charge that will not be required if additional units are ordered.

\section{FABRICATION OF ONE (1) CORNER UNIT ASSEMBLY}

The complete breakdown and cost for the fabrication of one (1) Corner Unit can be found in Appendix C. As with the A-Frame assembly, we included the costs for the CNC programming and processing as a line item cost. This is a onetime charge that will not be required if additional units are ordered.

FABRICATION OF ONE (1) A-FRAME REPLACEMENT CASSETTE

The complete breakdown and cost for the fabrication of one (1) A-Frame Replacement Cassette can be found in Appendix D.

FABRICATION OF ONE (1) CORNER UNIT REPLACEMENT CASSETTE

The complete breakdown and cost for the fabrication of one (1) Corner Unit Replacement Cassette can be found in Appendix $\mathbf{E}$.

\section{DELIVERY OF FABRICATED PARTS TO INL}

The costs to ship the assemblies from Warren, MI to INL in Idaho Springs Idaho are $\$ 19,488.00$. This includes a $10 \%$ administrative fee. The trucking quote can be found in Appendix $\mathbf{F}$.

\section{COST ESTIMATE FOR PRODUCTION UNITS (A-FRAME AND CORNER UNIT) PER SPC, SECTION 6}

The cost estimates can be found in Appendix G. There is an assembly tooling charge line item that is required for higher volumes that is amortized over the volume numbers. This tooling is not needed for one (1) to ten (10) unit builds.

The one (1) to ten (10) unit builds will not require the CNC programming and processing and is removed from the costs. 
RFP 2882740

Proposal

\section{V'WALTONEN}

\section{APPENDIX A}

The preliminary timing to produce the A-Frame and Corner barrier assemblies

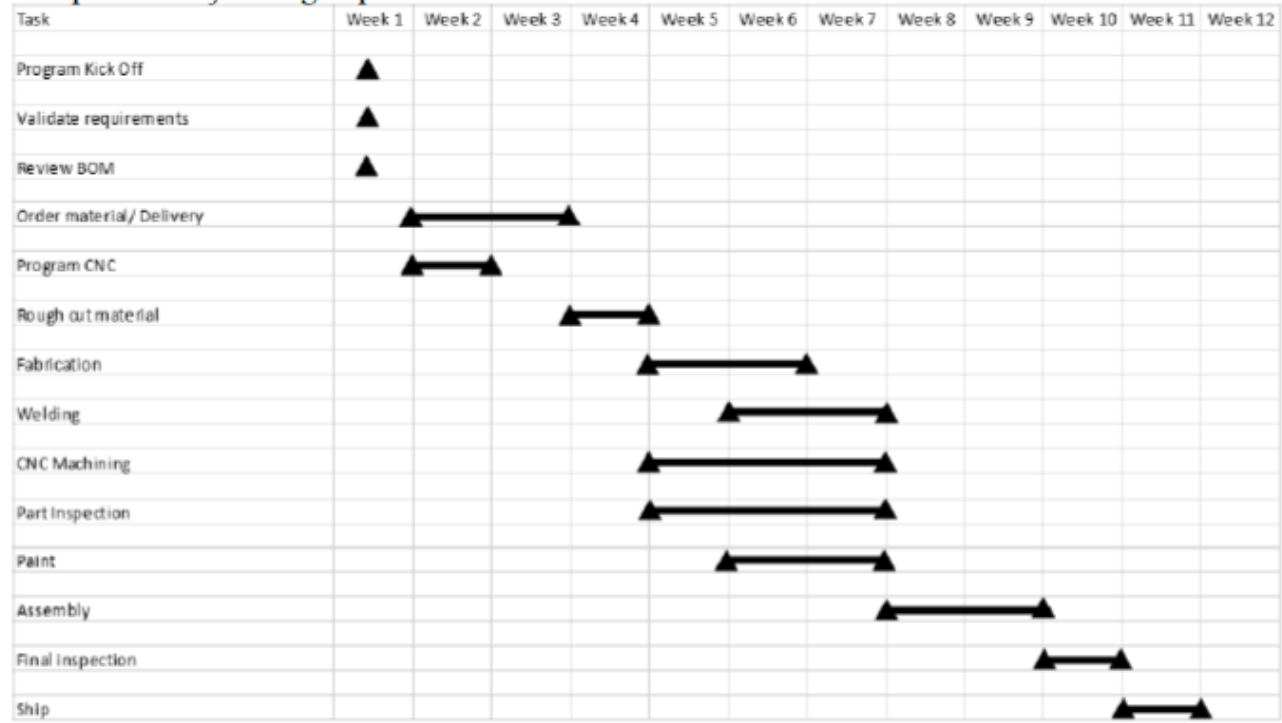

Ship 
RFP 2882740

Proposal

\section{V'WALTONEN}

\section{APPENDIX B}

Costs for one corner unit

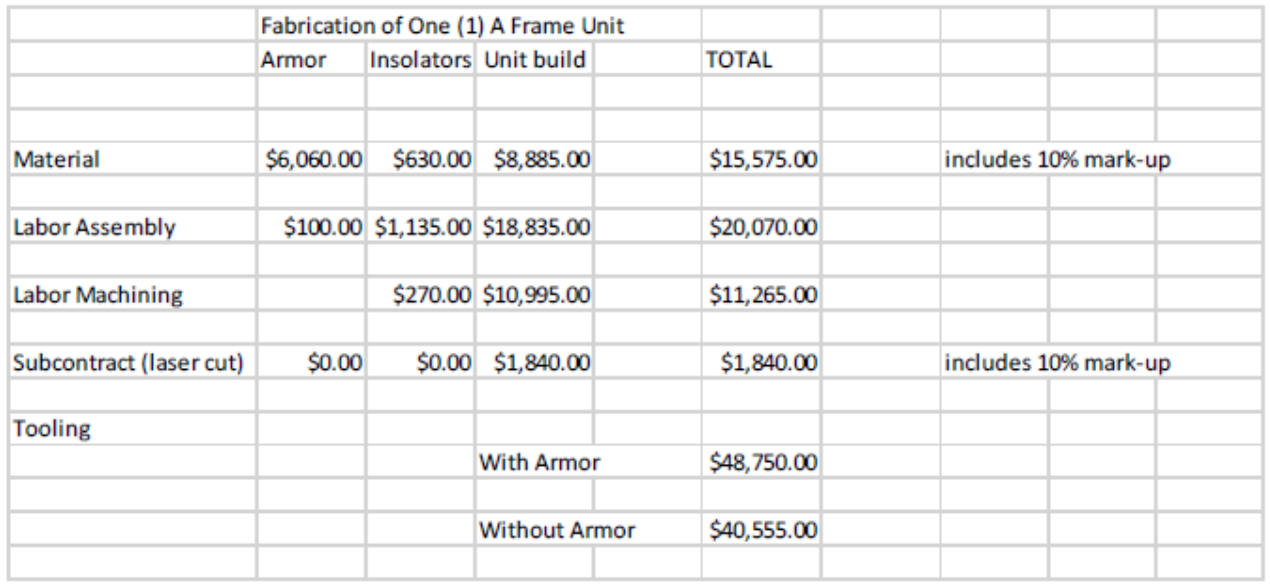


RFP 2882740

Proposal

\section{W'WALTONEN}

\section{APPENDIX C}

\section{Costs for one Corner Unit}

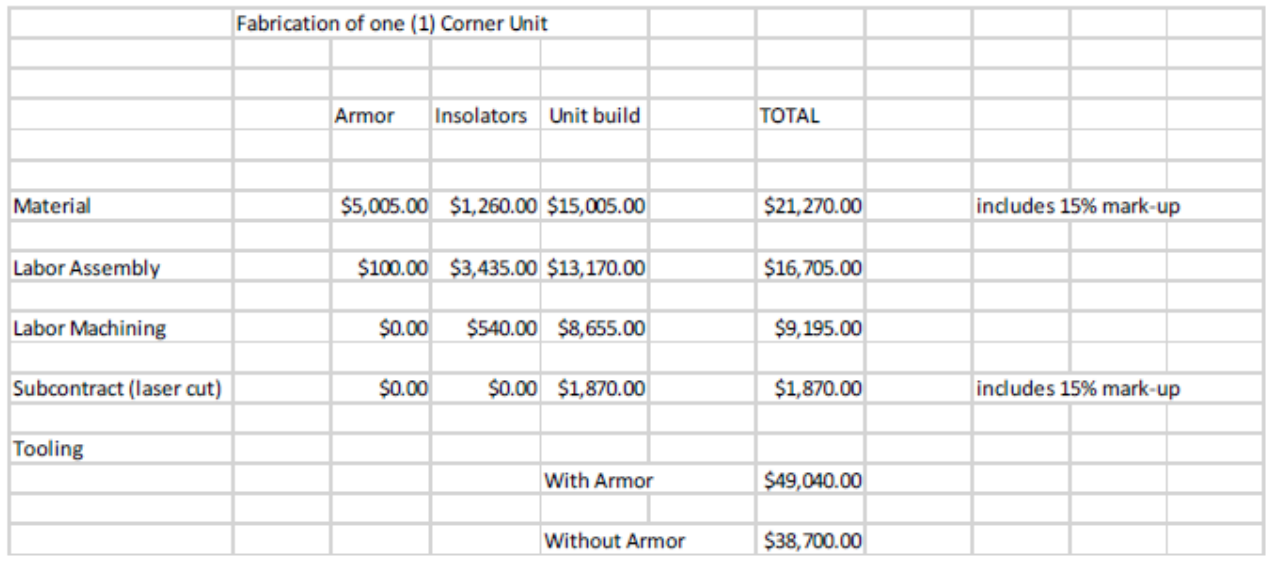


RFP 2882740

Proposal

\section{V'WALtonen}

APPENDIX D

Spare Cartridge A Frame Costs

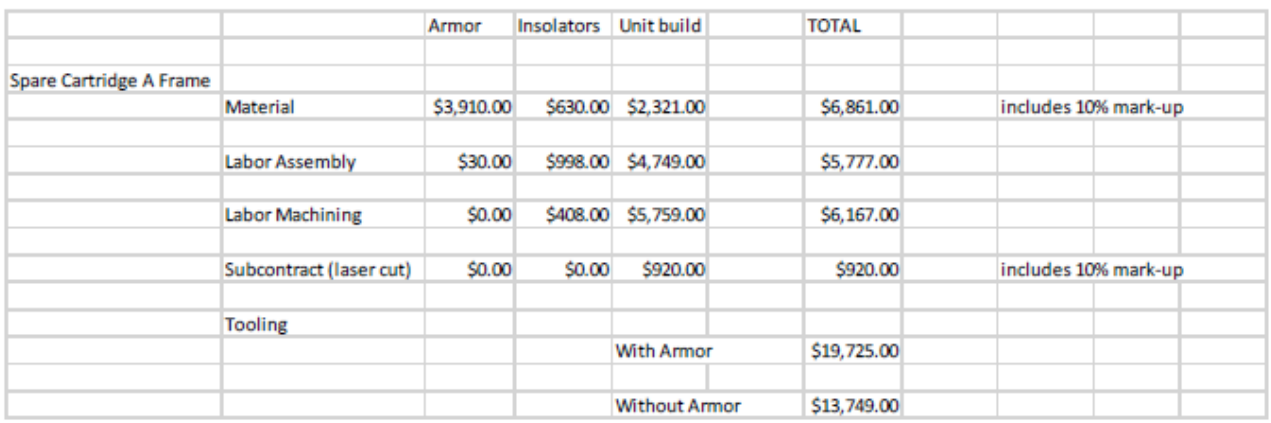

Use or disclosure of proposal data is subject to the restrictions on the title page of this proposal. 
RFP 2882740

Proposal

\section{V'WALTONEN}

\section{APPENDIX E}

Spare Cartridge Corner Unit Costs

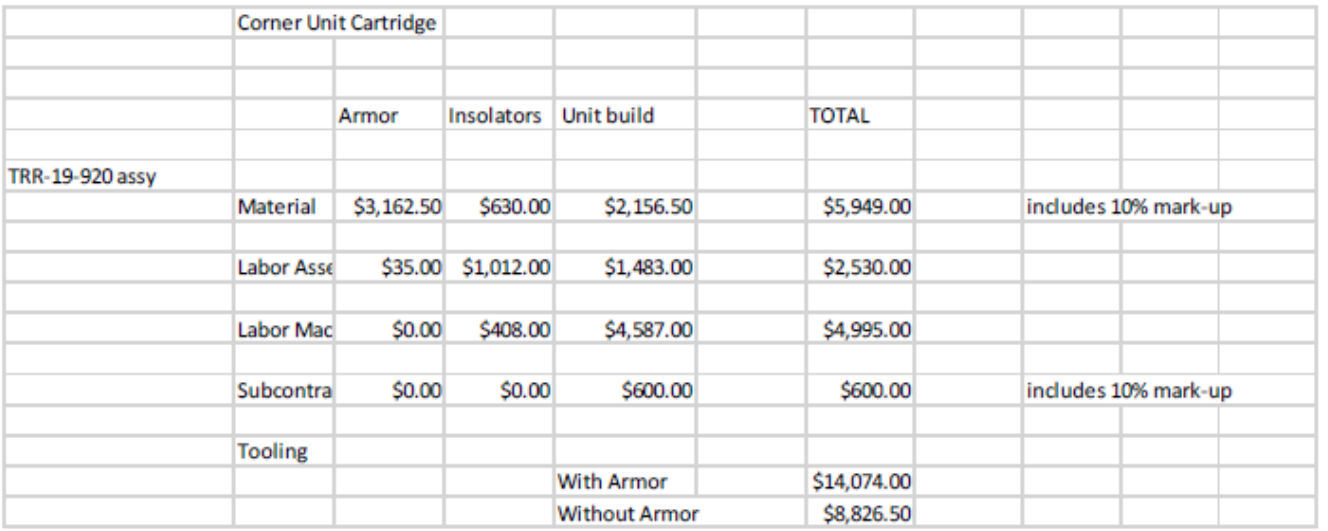

Use or disclosure of proposal data is subject to the restrictions on the title page of this proposal. 
RFP 2882740

Proposal

\section{APPENDIX F}

Trucking quote

\section{Rate Quote}

Step 1: Review Rate Quote

Pickup/Delivery Information

$\begin{array}{lllll}\text { Origin } & \text { 48208 MI } & \begin{array}{l}\text { Destination } \\ \text { Est. Delivery Date }\end{array} & 83403 \text { TBD } & \text { Payment Terms Prepaid } \\ \text { Eff. Shipment Date } & \text { TBD } & \text { Transit Days } & 5 \text { days } \\ & & \text { Volume Shipment Pricing }\end{array}$

This shipment qualifies for Volume Shipment Pricing, saving you $\$ 4,175.37$ compared to your original pricing. See below for additional details.

Charge

Volume Shipment Pricing Capped Price

$16,705.03$

Volume Shipment Fuel Surcharge

911.52 Excessive Length Shipment $\quad 100.75$

Rate Quote as of 1/31/2020 1:28 PM ET

Total Net charge (US Funds) $\$ \mathbf{\$ 1 7 , 7 1 7 . 3 0}$

5 days transit time 
RFP 2882740

Proposal

APPENDIX G

Volume build cost estimates

\begin{tabular}{|c|c|c|c|}
\hline & & 1 to 10 units & \\
\hline & & & \\
\hline & Unit Cost & CNC Programming & Total Cost \\
\hline A Frame & $\$ 48,750.00$ & $\$ 4,068.00$ & $\$ 44,682.00$ \\
\hline Corner Unit & $\$ 49,040.00$ & $\$ 2,853.00$ & $\$ 46,187.00$ \\
\hline
\end{tabular}

\begin{tabular}{|c|c|c|c|c|}
\hline \multirow[t]{2}{*}{ A Frame } & \multicolumn{3}{|c|}{ MANUFACTURE OF 11 TO 50 UNITS } & \multirow[b]{2}{*}{ TOTAL } \\
\hline & Armor & Insolators & Unit build & \\
\hline Material & $\$ 5,878.20$ & $\$ 611.10$ & $\$ 8,618.45$ & $\$ 15,107.75$ \\
\hline Labor Assembly & $\$ 97.00$ & $\$ 1,100.95$ & $\$ 16,972.09$ & $\$ 18,170.04$ \\
\hline Labor Machining & & $\$ 261.90$ & $\$ 9,215.00$ & $\$ 9,476.90$ \\
\hline Sub Contract & $\$ 0.00$ & $\$ 0.00$ & $\$ 1,784.80$ & $\$ 1,784.80$ \\
\hline (Laser Cut) & & & & \\
\hline Tooling & & & $\$ 437.00$ & $\$ 437.00$ \\
\hline & & & & $\$ 44,976.49$ \\
\hline
\end{tabular}

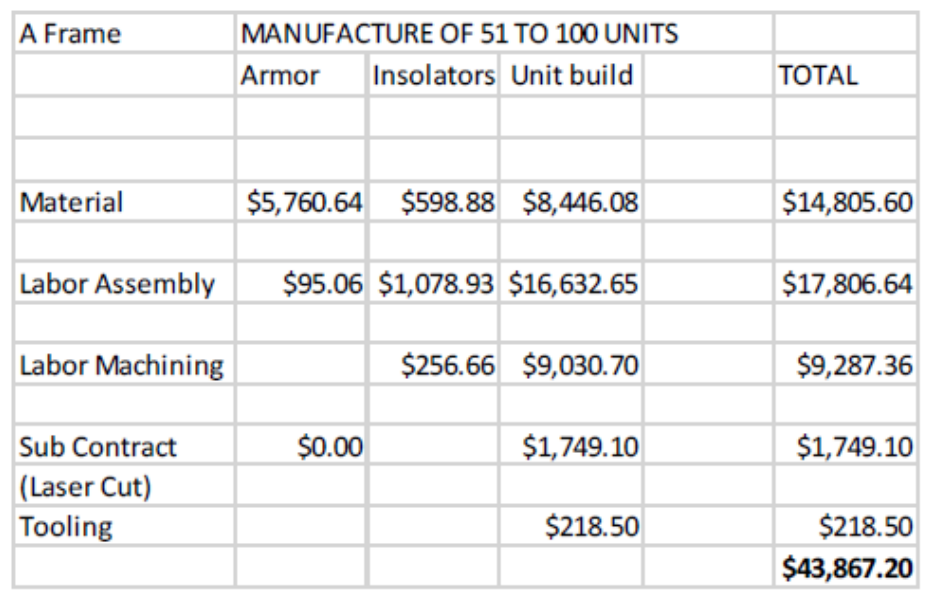


RFP 2882740

Proposal

V'WALtonen

\begin{tabular}{|c|c|c|c|c|}
\hline \multirow[t]{2}{*}{ A Frame } & \multicolumn{3}{|c|}{ MANUFACTURE OF 101 TO 500 UNITS } & \multirow[b]{2}{*}{ TOTAL } \\
\hline & Armor & Insolators & Unit build & \\
\hline Material & $\$ 5,616.62$ & $\$ 583.91$ & $\$ 8,234.93$ & $\$ 14,435.46$ \\
\hline Labor Assembly & $\$ 92.68$ & $\$ 1,051.96$ & $\$ 16,216.83$ & $\$ 17,361.47$ \\
\hline Labor Machining & & $\$ 250.25$ & $\$ 8,850.09$ & $\$ 9,100.33$ \\
\hline Sub Contract & $\$ 0.00$ & $\$ 0.00$ & $\$ 1,705.38$ & $\$ 1,705.38$ \\
\hline \multicolumn{5}{|l|}{ (Laser Cut) } \\
\hline \multirow[t]{2}{*}{ Tooling } & & & $\$ 43.70$ & $\$ 43.70$ \\
\hline & $\$ 5,709.30$ & $\$ 1,886.11$ & $\$ 35,050.92$ & $\$ 42,646.34$ \\
\hline
\end{tabular}

\begin{tabular}{|c|c|c|c|c|}
\hline \multirow[b]{2}{*}{ Corner Unit } & \multicolumn{3}{|c|}{ MANUFACTURE OF 11 TO 50 UNITS } & \multirow[b]{2}{*}{ TOTAL } \\
\hline & Armor & Insolators & Unit build & \\
\hline Material & $\$ 4,854.85$ & $\$ 1,222.20$ & $\$ 14,554.85$ & $\$ 20,631.90$ \\
\hline Labor Assembly & $\$ 97.00$ & $\$ 3,331.95$ & $\$ 10,511.41$ & $\$ 13,940.36$ \\
\hline Labor Machining & & $\$ 523.80$ & $\$ 7,890.95$ & $\$ 8,414.75$ \\
\hline Sub Contract & $\$ 0.00$ & $\$ 0.00$ & $\$ 1,813.90$ & $\$ 1,813.90$ \\
\hline \multicolumn{5}{|l|}{ (Laser Cut) } \\
\hline \multirow[t]{2}{*}{ Tooling } & & & $\$ 465.00$ & $\$ 465.00$ \\
\hline & & & & $\$ 45,265.91$ \\
\hline
\end{tabular}

Use or disclosure of proposal data is subject to the restrictions on the title page of this proposal. 
RFP 2882740

Proposal

W'waltonen

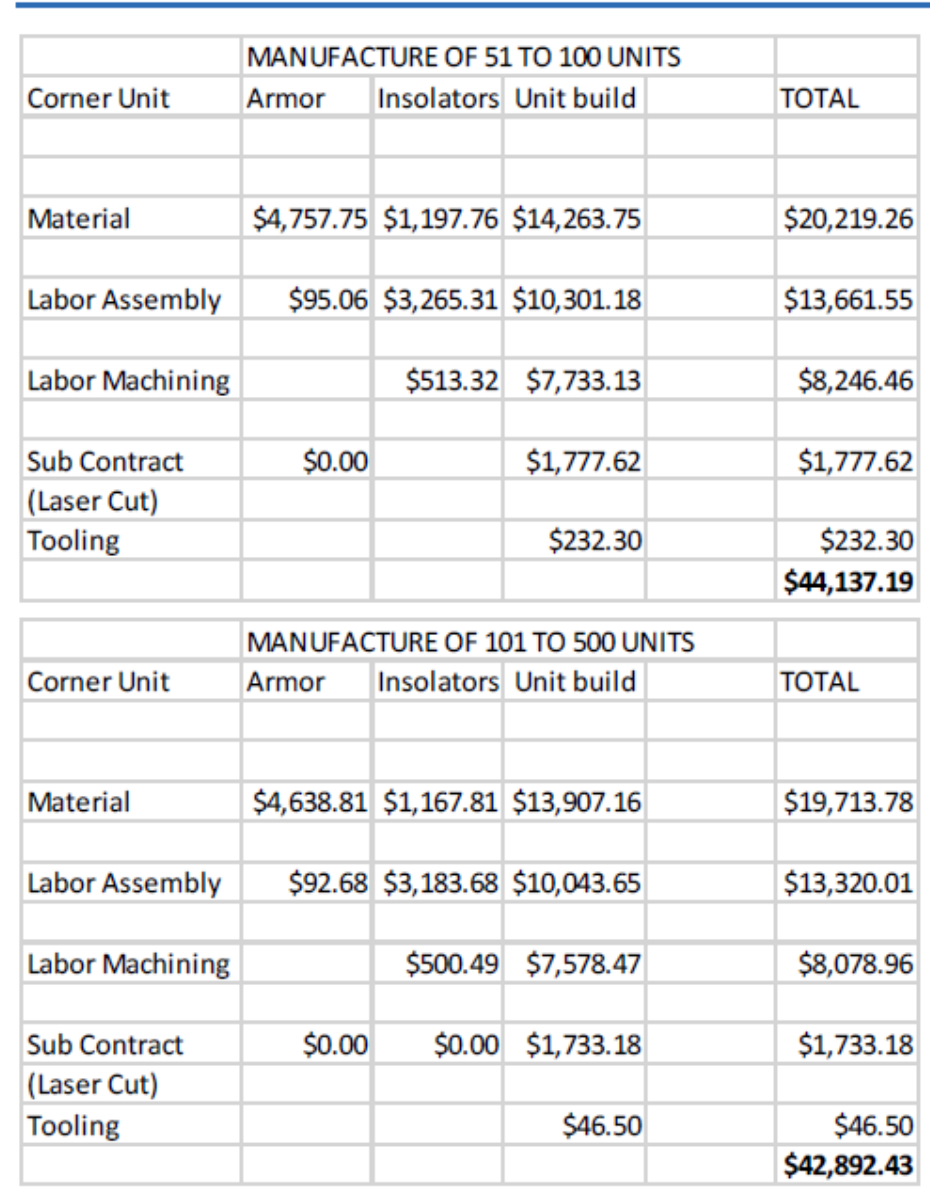

